\title{
Particle-based immobilized enzymatic reactors in microfluidic chips
}

\author{
Adam Kecskemeti, Attila Gaspar* \\ Department of Inorganic and Analytical Chemistry, University of Debrecen, Egyetem ter 1., Debrecen 4032, Hungary
}

\section{A R T ICLE INFO}

\section{Keywords:}

Microfluidic

Enzyme reactor

Particle

Enzyme immobilization

Protein digestion

\begin{abstract}
A B S T R A C T
The research and applications of immobilized enzyme reactors (IMERs) have become more and more widespread due to the numerous advantages like reusability, easy handling, prolonged lifetime, easy separation from products and substrate specificity. The miniaturized form of these reactors (microchip IMERs) received outstanding attention due to their special features and advantages over the traditional, larger analytical systems. Large specific surface is essential for the efficient operation of the microreactors, thus these devices include one of the several types of porous solid supports, but in this work only the particle based microchip IMERs are reviewed. A very large variety of micro- or nanoparticles (beads) have been used in the microchip IMERs, however, incorporating these particles into microchips is still a challenge, because the common procedures used for the preparation of chromatographic columns are not well applicable at the microscopic level.

Many detection systems were applied with microchip IMERs using on-chip or off-chip arrangement. The combination of microchip IMERs with mass spectrometry is particularly popular, because in these systems high-throughput analysis can be achieved by which the proteomic studies can be largely accelerated. In most chip IMER-MS systems, the chips are used for sample pretreatment including analyte (protein) digestion, preconcentration of analyte, removal of matrix materials. Additional applications of the IMERs - like the rapid protein digestion with proteolytic enzymes, the transformation of analytes to a more easily or more sensitively measurable form (detection signal amplification) and the design of microarrays/biosensors to analyze antigens based on specific interactions in immunoanalytical studies - are also reviewed.
\end{abstract}

\section{Introduction}

The application of enzymes in different industrial (mainly biotechnological) and analytical areas has been increasing in the last few decades. Enzymes are more and more often used in microreactors, which are a wide range of devices built by micrometer scale capillaries or channels [1]. The enzymes can be immobilized on different supports in flow systems, the obtained devices are termed as immobilized enzyme reactors (IMERs). IMERs can be applied in many pieces of equipment built from standard laboratory or industrial parts (e.g. tubes, reactors), but also in microfluidic devices, when a maximum of a microliter sample/reagent volume is applied (microfluidic IMER). In the literature, a discrepancy exists as IMER is considered both as an exclusively microfluidic system [2-5] and also as a larger ("macroscopic") system [6-8]. According to the most often used definition of microfluidics (transporting and manipulating $\mu \mathrm{L}$ amounts of fluid through a microchannel), reactors integrated into microcapillary devices (e.g. capillary electrophoretic (CE), micro/nano liquid chromatographic (LC) or micro flow injection analysis ( $\mu$ FIA) systems) should be considered as microfluidic IMERs. When the whole microfluidic IMER equipment is smaller than around an ID card (few tens of $\mathrm{cm}^{2}$ ) the microfluidic chip-based IMER (or shortly microchip IMER) term is suggested. Microfluidic chips are receiving increasing attention due to their special features and advantages over the traditional, larger analytical systems [9].

Abbreviations: AChE, acetylcholinesterase;; APTES, (3-aminopropyl)triethoxysilane; BAEE, No-benzoyl-L-arginine ethyl ester; BSA, bovine serum albumin; CE, capillary electrophoresis;

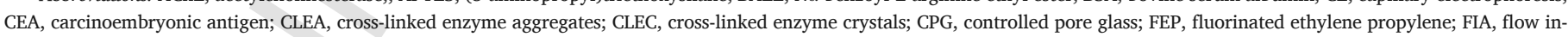

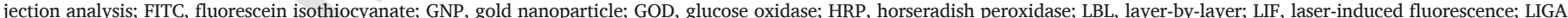

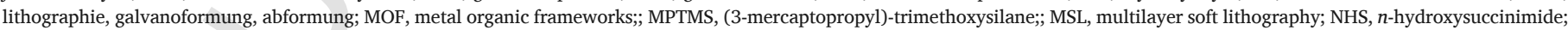

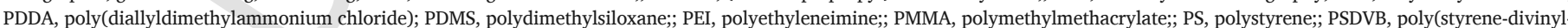
benzene); PVA, polyvinyl alcohol; S/V, surface to volume; SPE, solid phase extraction; XOD, xanthine oxidase; $\mu \mathrm{CP}$, microcontact printing.

* Corresponding author.

Email address: gaspar@science.unideb.hu (A. Gaspar) 
The IMER - especially the microchip IMER technology - has a strong interdisciplinary nature since it needs to combine and utilize natural sciences and engineering. For the design and preparation of microchips with enzymatic reactors, different microelectronical and micromechanical technologies are needed, enzyme immobilization requires strong chemical knowledge, special areas of physics are used for the proper operation/control of flows in the microscopic channel system and the IMERs are mostly applied in analytical, pharmaceutical, diagnostical, environmental and biotechnological fields.

There are numerous advantages of using immobilized enzymes: reusability, easy handling, prolonged lifetime, easy separation from products and substrate specificity. Also, it was proved that immobilized enzymes were stable and resistant to the changes in the environmental conditions [10]. The chip-type microreactors offer additional advantages over the capillary-type reactors, like versatile applications and easy control of liquid flows, and integration of several processes into a single unit. The networks of microchannels, due to the large surface area to volume ratios (S/V ratio), provide large specific surface for catalytic reactions or extractions. There are many works where the thermal homogeneity across the reactor and rapid heat transfer between the device and the contained liquid were utilized [3]. In microchip IMERs, the microscale reactors require only a very small amount of (often expensive) enzymes/reagents. On the other side, since only nanoliter volumes of sample and reagents are applied in chips, the diffusion induced/limited reactions are considerably faster than those would be in larger volumes with conventional batch systems. Although microchip IMERs are not applicable to produce large amounts of products, the main goal of chemists can often be the production of a minimal amount of compound (e.g. for chemical informatics, identification, analysis). As in most microfluidic systems, the scale-out option by parallelization is also possible to enable high-throughput operation. Intense parallelization can be the key approach to remedy the weakness of microchip IMERs, making the production/synthetization of compounds possible in the mg range or higher. In microchips, several sequential steps might be integrated, which can either be multi-step enzyme reactors or enzyme reactors integrated to other microfluidic devices (for separation, enrichment, derivatization, detection, etc.). The advantages of IMERs regarding the short reaction/analysis time, high efficiency in catalytic reactions were thoroughly discussed in many papers and reviews $[3,4]$.

One of the best possible IMER designs is to use microchips as solid supports for immobilization [5,6,11-15]. Although the microscopic channel network possesses quite a large $\mathrm{S} / \mathrm{V}$ ratio, solid supports with even higher specific surface area (e.g. membranes [16-19], monoliths [20-30], magnetic microspheres/beads [31-41], silica particles (packing or column) [42-45], commercially available beads (usually cross-linked agarose) [46-49], etc.) can be integrated into chips to further increase the $\mathrm{S} / \mathrm{V}$ ratio of the reactor. The small and highly porous chromatographic particles provide the highest $\mathrm{S} / \mathrm{V}$ parameter. The size of the particles is in the nano- or micrometer range and those can be used in suspension or in packing format to build microreactors. To fill out the channels properly, spherical particle shape is the most favored. The particles used in IMERs are made from silica [42-45,50,51], glass [52-56], agarose [46-49,57,58] or different polymers [59-75]. Quite a wide range of commercialized porous particles are accessible, however, their integration into flow systems - that are retaining and preparing stable, compact and durable packings in the microscopic channels of a chip - remains a challenge.

While non-microchip IMERs are used almost exclusively for applications in organic synthesis and biotechnology [51,56,59-63,71-73,75], microchip IMERs are mostly used for analytical applications. These analytical aims include the rapid protein digestion utilized in proteomic related works [31-36,43,46-49,76-82], the transformation of analytes to a more easily or more sensitively measurable form [37-39,42,44,52-54,57,68-70,83] and the design of microarrays/ biosensors to analyze antigens based on specific interactions in immunoanalytical studies [40,65-67].

A great potential of microchip IMERs is that - according to the lab-on-a-chip conception - the microfluidic chip might integrate sample pretreatment [84], separation/preconcentration [85] and detection units [86] besides the enzymatic reactor itself. Thus, in addition to the efficient and fast enzyme operations, microchip IMERs can be hyphenated with pretreatment, separation and detection systems to achieve high-throughput analysis.

In the last 30 years, hundreds of articles have been published about IMERs in chemical and analytical chemical journals (Fig. 1), the number of the reviews exceeded 25. In Table 1 . the recent reviews published between 2010 and 2016 were summarized. Since a very large number of papers and reviews have been issued, in our work we have focused on the particle-based microreactors, subsequently, the reactors incorporating monoliths, membranes, capillary/channel walls would not be covered here. Instead, recent developments of the designs, structures, fabrication and applications of particle based microchip IMERs are highlighted with illustrative examples as well as the critical comparison of the merits and limitations of the various published approaches.

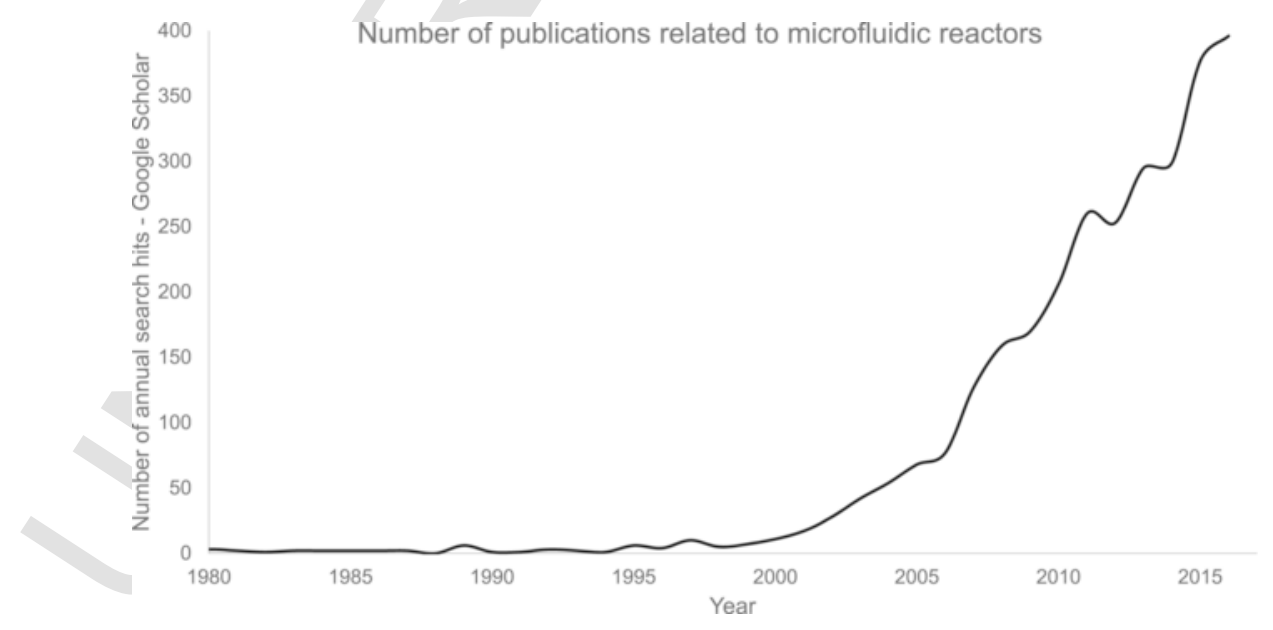

Fig. 1. Number of annual publications related to microfluidic reactors (searching with Google Scholar). 
Table 1

Recent reviews of immobilized enzymatic reactors (2010-2016).

\begin{tabular}{|c|c|c|}
\hline Ref. & Title & Keywords $(\max .4)^{\mathrm{a}}$ \\
\hline [173] & $\begin{array}{l}\text { Efficient proteolysis strategies } \\
\text { based on microchip bioreactors }\end{array}$ & $\begin{array}{l}\text { Microfluidic chip, } \\
\text { Proteolysis, Bioreactor, } \\
\text { Proteomics, Protease, Mass } \\
\text { spectrometry }\end{array}$ \\
\hline [97] & $\begin{array}{l}\text { Protein immobilization } \\
\text { techniques for microfluidic } \\
\text { assays }\end{array}$ & \\
\hline [174] & $\begin{array}{l}\text { Continuous-flow biochemical } \\
\text { reactors: biocatalysis, } \\
\text { bioconversion, and bioanalytical } \\
\text { applications utilizing } \\
\text { immobilized microfluidic enzyme } \\
\text { reactors }\end{array}$ & $\begin{array}{l}\text { Continuous-flow } \\
\text { biochemical reactor, Enzyme } \\
\text { immobilization, } \\
\text { Microreactors, Biocatalysis, } \\
\text { Bioconversion, Bioanalytics }\end{array}$ \\
\hline [175] & $\begin{array}{l}\text { Potential applications of enzymes } \\
\text { immobilized on/in nano } \\
\text { materials: A review }\end{array}$ & $\begin{array}{l}\text { Nanoparticles, } \\
\text { Immobilization, Biosensors, } \\
\text { Biomedical applications }\end{array}$ \\
\hline$[2]$ & $\begin{array}{l}\text { Enzyme-immobilized reactors for } \\
\text { rapid and efficient sample } \\
\text { preparation in MS-based } \\
\text { proteomic studies }\end{array}$ & $\begin{array}{l}\text { Enzyme immobilization, } \\
\text { Protease, Proteolysis, } \\
\text { Proteomics, Stability }\end{array}$ \\
\hline [145] & $\begin{array}{l}\text { Application of enzyme- } \\
\text { immobilization technique for } \\
\text { microflow reactor }\end{array}$ & $\begin{array}{l}\text { Microreactor, Enzyme, } \\
\text { Immobilization, } \\
\text { Biotransformation }\end{array}$ \\
\hline [176] & $\begin{array}{l}\text { Microscale immobilized enzyme } \\
\text { reactors in proteomics: Latest } \\
\text { developments }\end{array}$ & $\begin{array}{l}\text { Proteomics, Microfluidics, } \\
\text { Enzyme reactor, Enzyme } \\
\text { immobilization, } \\
\text { Miniaturization, Monolith }\end{array}$ \\
\hline [177] & $\begin{array}{l}\text { Review of the applications of } \\
\text { microreactors }\end{array}$ & $\begin{array}{l}\text { Modify structured } \\
\text { microreactors, } \\
\text { Microchannel, Microfluidic } \\
\text { catalytic film }\end{array}$ \\
\hline [178] & $\begin{array}{l}\text { Enzyme immobilization: an } \\
\text { update }\end{array}$ & $\begin{array}{l}\text { Enzyme immobilization, } \\
\text { Biocatalyst, Enzyme reuse }\end{array}$ \\
\hline [179] & $\begin{array}{l}\text { Enzyme-immobilized } \\
\text { microfluidic process reactors }\end{array}$ & $\begin{array}{l}\text { Microfluidic reactor, } \\
\text { Microreactor, } \\
\text { Immobilization, } \\
\text { Bioconversion }\end{array}$ \\
\hline [180] & $\begin{array}{l}\text { Microreactors: a new concept for } \\
\text { chemical synthesis and } \\
\text { technological feasibility }\end{array}$ & \\
\hline [150] & $\begin{array}{l}\text { Integrated microreactors for } \\
\text { reaction automation: new } \\
\text { approaches to reaction } \\
\text { development }\end{array}$ & $\begin{array}{l}\text { Microfabrication, Online } \\
\text { reaction monitoring, } \\
\text { Chemical synthesis, Reaction } \\
\text { optimization }\end{array}$ \\
\hline [3] & $\begin{array}{l}\text { The past, present and potential } \\
\text { for microfluidic reactor } \\
\text { technology in chemical synthesis }\end{array}$ & \\
\hline [4] & $\begin{array}{l}\text { Microchannel enzyme reactors } \\
\text { and their applications for } \\
\text { processing }\end{array}$ & \\
\hline [181] & $\begin{array}{l}\text { Accelerating trypsin digestion: } \\
\text { the immobilized enzyme reactor }\end{array}$ & \\
\hline [182] & $\begin{array}{l}\text { Enzyme nanoarchitectonics: } \\
\text { organization and device } \\
\text { application }\end{array}$ & \\
\hline [183] & $\begin{array}{l}\text { Microfluidic devices: useful tools } \\
\text { for bioprocess intensification }\end{array}$ & $\begin{array}{l}\text { Microfluidic devices, } \\
\text { Bioprocess intensification, } \\
\text { Modelling and simulation }\end{array}$ \\
\hline [184] & $\begin{array}{l}\text { Fundamentals and applications } \\
\text { of immobilized microfluidic } \\
\text { enzymatic reactors }\end{array}$ & $\begin{array}{l}\text { Microfluidics, Enzymes, } \\
\text { Biocatalysis, Kinetics, } \\
\text { Reactors }\end{array}$ \\
\hline
\end{tabular}

a The keywords were obtained from the given paper.

\section{Fabrication of particle-based IMERs}

\subsection{Preparation of microchips}

\subsubsection{Designs and materials of microchips}

In microchips, many interconnected microchannels and varied shapes of microdevices (chambers, reactors, etc.) are fabricated. The manufacturing of microchips was adapted mainly from the microelectronical industry. In the beginning, the microchannels were created in hard materials like silicone [87], quartz or glass [46] using dry or wet etching procedures. Later, mainly polymer-based materials like Teflon, polymethylmethacrylate (PMMA), polycarbonate, epoxy-based SU8 or polydimethylsiloxane (PDMS) were preferred due to their easier fabrication [88]. These polymers offer several advantages as they are transparent, non-toxic (often biocompatible) and cheap. Polymer microchips can be manufactured by photolithography (including laser ablation [89]), soft lithography [90], injection molding and different micromachining techniques [91]. These technologies are often combined, as in LIGA process [91]. In general, all polymer fabrications make replicas from a master mold, which contains the structure of the microscopic design.

Many microfluidic chips include open channel architecture providing high $\mathrm{S} / \mathrm{V}$ ratio, which is beneficial for chromatographic separations, heterogeneous catalysis or solid-phase extraction. The microchips typically operate in flow mode, therefore their on-line coupling with high performance separation and/or detection methods (LC, CE, MS) is relatively easy to accomplish. The liquid flows in the microchannels can be driven by pressure or electric field (electroosmotic flow), but the electrokinetic system can be miniaturized more easily and small segments of samples or reagents can be more precisely manipulated by time-programmed application of voltages at different positions on the chip (e.g. transportation and injection of sample, electrophoretic separation, destaining procedure in Bioanalyzer 2100 (Agilent) [92]).

Recently, the polymer most extensively used for fabrication of microchips is PDMS. It is a low-cost polymer and a supreme adsorbent, which is widely used for microfluidic, optical, and nanoelectromechanical structures and in low-cost replication processes such as replica molding and templating. In order to make microchips, almost exclusively the method of soft lithography is applied, especially if biological applications are targeted (non-toxic to cells, permeable to gases, non-dissolvable in water) [93]. Since microchip IMERs may operate with proteins and enzymes, the adsorption properties of proteins on the material of the chip must be thoroughly studied. This issue is particularly important in the case of PDMS, because proteins adsorb very strongly (practically irreversibly) to the porous and hydrophobic surface of PDMS [15,94]. The characterization and modification of PDMS were studied and discussed in several papers [94-96]. Immobilization strategies for a wide range of enzymes have been developed for PDMS [97]. In contrast to the many above-mentioned advantages of PDMS, it is also obvious that although recently PDMS is the most favorable material for microchip preparation in research laboratories due to its simplicity and cheapness, it does not seem to be an attractive choice for commercial manufacturing (perhaps because of its low durability and easy shattering).

\subsubsection{Methods of particle retention}

Micro- or nanoparticles (beads) are often used in analytical systems, particularly for chromatographic separations, immunoassays or reactors. However, incorporating these particles into microchips is still a challenge, because the common procedures used for the preparation of chromatographic columns are not well applicable at the microscopic level. The bead-based assays in microfluidic systems were reviewed by Verpoorte [98]. 
Firstly, Manz retained $5 \mu \mathrm{m}$ C8 particles by frits in a microcolumn integrated onto a silicon chip in order to miniaturize liquid chromatography [99]. Since the packing process including frit preparation was difficult (it cannot be easily fabricated within a microfluidic architecture, formation of bubbles and band-broadening is frequently observed), the subsequent attempts to make chromatographic chips applied open-tubular approaches $[100,101]$. Other devices have incorporated a physical barrier (e.g. weir, dam, bead chamber) to localize chromatographic stationary-phase particles [102], derivatized beads for immunoassay [65] or for heterogeneous catalysis [68]. Since the use of frits is problematic, fritless columns employing tapered capillary geometries have been used [103-105]. At the taper, the density of the particles increases and they aggregate without the need of a frit or physical barrier. The first particles act as keystones, blocking the other particles and allowing the packed section to increase in length. Experiments showed that it was only necessary to taper the capillary to approx. $10 \mu \mathrm{m}$ (inner diameter) to achieve the keystone effect and to retain $3 \mu \mathrm{m}$ sized silica beads [103]. Ceriotti et al. [105] stabilized the packing by placing the packed capillary in an oven for overnight incubation $\left(115^{\circ} \mathrm{C}\right)$. They supposed that an interparticle bonding is formed during heating, as a thin surface layer of the particles is dissolved in water, forming a saturated solution of polysilic acids, which redeposits as silica between the particles after cooling [106].

We reported that even temporary tapering of the channel in a microchip $[107,108]$ or a bottleneck shape of a short channel formed in the chip [109,110] can lead to effective particle retention. Different retaining effects appearing in the packed channel due to the flexibility of the PDMS channel wall have been observed and discussed [107]. The chromatographic beads were pressed together by the forces of the elastic strains acting perpendicularly from the wall toward the middle of the channel (clamping-effect). Besides, the hard silica beads adjacent to the soft PDMS wall deform and partly penetrate the wall, which act as anchors for the packing. The packing of particles into the microfluidic channels was made possible by both the hydrophobic nature and excellent elasticity of PDMS. The bulk properties of PDMS include a low Young's modulus ( $\mathrm{E}=0.5-4 \mathrm{MPa}$ depending on the curing conditions) and high Poisson ratio ( $\mathrm{v}=0.5$ that is essentially incompressible)

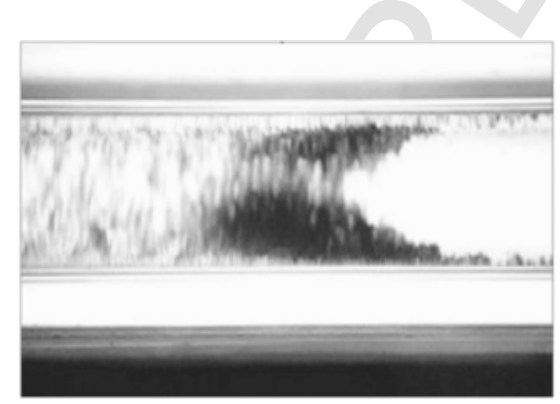

a

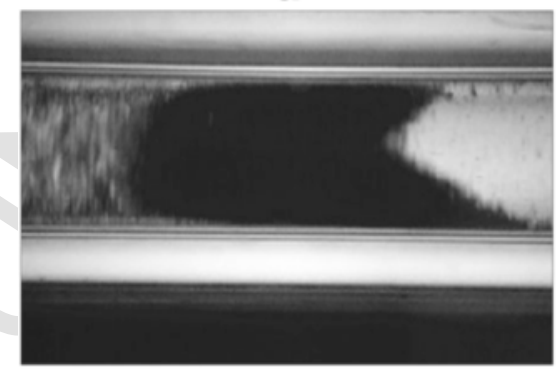

C making it a rubber-like material [111]. The simplicity of this method made it possible to fabricate microfluidic chips incorporating multi-channel systems packed with conventional chromatographic particles without the use of frits [110].

Huft et al. [112] reported about a low-pressure bead packing technique for the robust integration of parallel chromatographic columns in PDMS microchips made by multilayer soft lithography (MSL) [113]. They used pneumatically operated microvalve control systems and arrays of bypass channels for packing. After the packing preparation, the control channel system should be continuously held under pressure, otherwise the chromatographic particles escape from the channel, which largely limits the long-term applicability of the packing.

Conventional 3.5- and 5- $\mu \mathrm{m}$ beads were retained in the Agilent's HPLC-chip-MS system for high efficiency chromatographic separation [114]. The chip and the frit structures for retaining the particles were fabricated by laminating thin polyimide layers microfabricated by laser ablation. Both the enrichment and separation micropackings were created from a suspension of microbeads, which was then injected through an inclined glass capillary that has a constriction at its outlet to retain the beads.

Instead of making a compact packing in a microchip, particles can be retained on the surface of the channels various ways. One way to capture a monolayer (or a few layers) of beads can be performed by attracting magnetic beads with magnetic forces onto the surface [115]. With the externally positioned magnets, magnetic beads can be freely manipulated within the microchannels, but this technique can even be used to form packings in the channels and not only at the wall (Fig. 2). There are a number of other ways to retain particles exclusively on the surface of capillary channels. Layer-by-layer (LBL) modification can be carried out by depositing a charged polymer (e.g. poly(diallyldimethylammonium chloride) (PDDA)) and gold nanoparticles (GNPs) alternatingly onto the channel surface [78]. Another way is to retain particles in a microchip when a layer of self-assembled beads is formed. By microcontact printing technology $(\mu \mathrm{CP})$ a pattern of different surface functionalities can be generated and beads with different functional groups are then self-arranged onto the pattern. For instance, a biotin-labeled albumin is printed, and then the beads with complementary compound (streptavidin) can be self-arranged as a monolayer on the

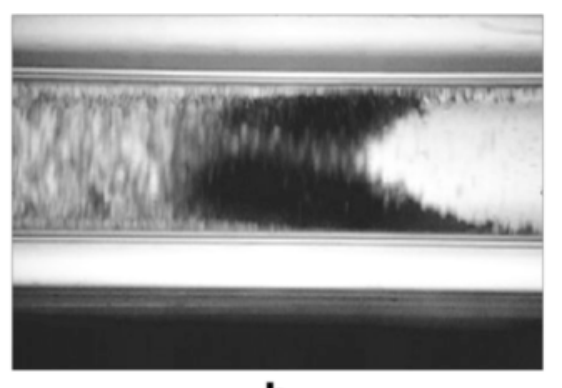

b

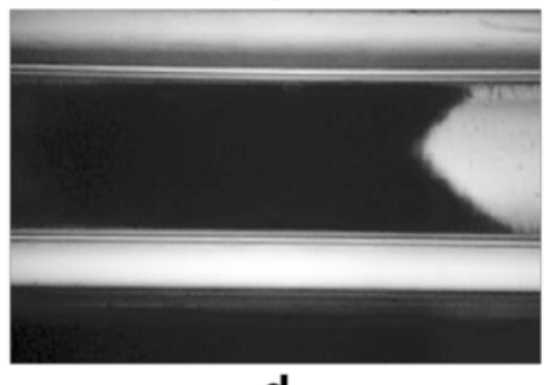

d

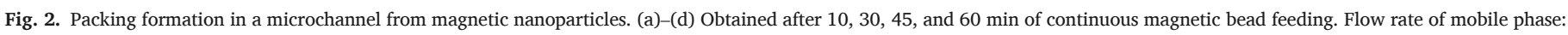
$1 \mathrm{~mL} / \mathrm{h}$. (Adapted from Ref. [35]). 
printed pattern [116]. The self-assembled beads were stable within the chip channels against the liquid flow. A similar method is called particle entrapment, which can be accomplished if the surface of a microfluidic chip is gel-derived [81,117]. Silane functional groups are first introduced to the surface and a stable gel matrix is further formed by silicon - oxygen - silicon bridges. Furthermore, entrapment of silica particles on the surface of a PDMS chip can be carried out by simply casting the PDMS to a dried portion of silica particles deposited on the mold during the microchip fabrication $[118,119]$.

\subsection{Particles}

The notable advantages of using particles integrated into microfluidic systems should not be ignored. Particles usually provide an elevated specific surface area, for example $1 \mathrm{~g}$ of microbeads with a diameter of $0.1 \mu \mathrm{m}$ has a total surface area of about $60 \mathrm{~m}^{2}$ [120]. This property can be well-utilized in heterogenic reactions, mostly when the enzyme is attached to a solid surface, while its substrate is in the liquid phase. On the one hand, the smaller the particles are, the larger the total surface becomes. On the other hand, in this way more densely packed packings are obtained, consequently, thinner fluid layers are formed between the neighboring particles (smaller dead volume), leading to faster transport [98], which is essential for rapid heterogeneous reactions. Another contributor to rapid heterogenic reactions is porousness, as porous particles possess even higher specific surface.

The following classification of particles used as solid supports in IMERs is based on the sizes of the applied particles, as we want to emphasize the role of particles in these systems. For easier understanding, Fig. 3 sums up the most widely used particles. As can be seen, there are overlaps between these categories (meaning that a certain particle can vary in size), in which case particles are listed under the more characteristic group.

\subsubsection{Nanoparticles}

As nanotechnology enters almost all branches of scientific research, medicine and industrial applications, the immobilization of enzymes onto nanomaterials or nanostructures (spheres, tubes, rods, wires, fibers etc.) becomes more and more widespread. Nanoparticles are particles between 1 and $100 \mathrm{~nm}$ in at least one dimension; they are usually made of inorganic materials like silica, gold (GNPs) or iron oxide $\left(\mathrm{Fe}_{3} \mathrm{O}_{4}\right)$. As the microscale particles, channels, liquids often behave differently than the conventional, macroscopic systems, it is particularly true for the nanoparticles (colloidal properties). In this subchapter, nanozeolites, GNPs and metal organic frameworks (MOFs) are discussed in detail. 2.2.1.1. Gold nanoparticles The application of GNPs has the advantage of relatively easy preparation and straightforward surface chemistry (proteins can be bound directly onto its surface). The interaction between protein and gold can either be hydrophobic, ionic or covalent (dative) bond through the cysteine residues [121]. It was also shown, that cysteine-tagged proteins are more likely to maintain their original conformation, therefore their application can be advantageous [122].

L-asparaginase was adsorbed on GNPs that were bonded to the surface of a glass microchip [123]. In this setup, (3-mercaptopropyl)-trimethoxysilane (MPTMS) was used for the surface modification of the capillary channel and the GNPs were bonded to the surface by the dative bond between gold and sulfur. The purpose of this study was to examine the enzyme kinetics of L-asparaginase.

Although nanoparticles are typically nonporous, they possess large specific surface area due to their nanometer scale size. However, nanozeolites and MOFs are porous nanomaterials, which furtherly increase their specific surface area.

2.2.1.2. Nanozeolites Nanozeolites are aluminosilicate nanoparticles/ crystals with different structure codes (LTL, Beta, Silicalite-I), usually formed hydrothermally [124-126]. The less than $100 \mathrm{~nm}$ crystals possess excellent adsorptive properties, proteins readily adsorb on their surfaces. From the aforementioned types, LTL provides the highest adsorptive capacity towards trypsin, probably due to the highest specific surface area [81], the adsorption occurs according to the multilayer adsorption mechanism. These particles were entrapped into a sol-gel matrix and they were used for proteolytic digestion in a PMMA microfluidic chip $[81,82]$.

2.2.1.3. Metal organic frameworks Recently metal organic frameworks (MOFs) are being developed and used to immobilize enzymes for microreactors, however, microfluidic applications have not yet been demonstrated. MOFs are coordination polymers consisting of metal ions and organic linkers providing a wide variety of shapes, pore sizes and applications, including enzymatic catalysis with immobilized enzymes $[127,128]$. The main hindrance of using MOFs is their very small pore size, as enzymes are unable to diffuse into them to be adsorbed. Consequently, some attempts were made to immobilize fluorescein isothiocyanate-tagged (FITC-tagged) trypsin, when FITC was bound in the pores [127]. Another approach is to form a complex between trypsin and the metal atom $\left(\mathrm{Zn}^{2+}\right)$ of the MOFs or to introduce amino functionalities onto the surface of the MOFs during the synthesis and covalently couple trypsin to these [129]. However, these attempts did not integrate the particles into microfluidic chips.

An intriguing outlook of these works would be the use of hybrid monoliths with embedded nanoparticles or MOFs in microfluidic chips. Although there are attempts to create such systems [129,130], they apply capillary reactor formats. The integration of these reactors into a microchip platform would not only be impressive, but would also supply additional advantages derived from the characteristics of these systems. 2.2.1.4. Emulsion A refreshing 'particle-based' microfluidic reactor was described by Pohar et al. [131]. Lipase enzyme catalyzed the formation of isoamyl acetate in a glass microchip. The enzyme was not immobilized in a classical manner, but an ionic liquid/n-heptane emulsion was created, the enzyme was added to this liquid system and it acted as a surfactant. It was located at the interfacial area due to its amphiphilic

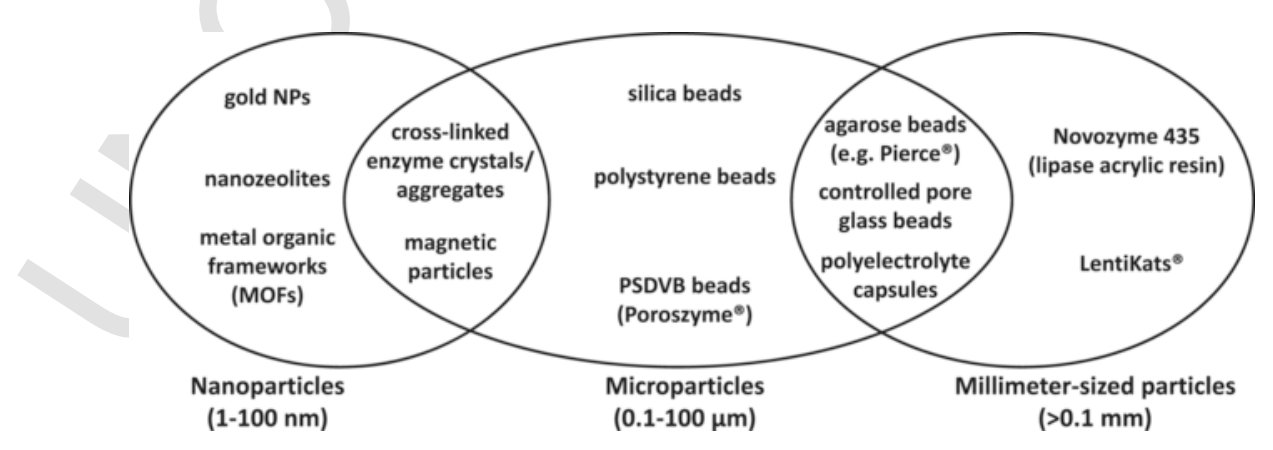

Fig. 3. Classification of different particle types based on their sizes. 
property, thus, catalysis occurred on the surface of n-heptane liquid 'particles'. The reaction was considerably faster than in the case of batch reactions with vigorous mixing in test tubes.

\subsubsection{Microparticles}

Microparticles are particles between 0.1 and $100 \mu\{\backslash$ displaystyle $\backslash \mathrm{mu}\} \mu \mathrm{m}$ in size. Such particles can be made from several materials (e.g. glass, silica, metals, polymers, etc.) and those are often commercially available. Micrometer-scaled particles are favorably applied in microchips for their extremely large variety and ease of retention by frits, bottlenecks, wires or dams. It is interesting to compare, that microparticles are usually used in a packing format, while nanoparticles are primarily used in an entrapped format, at the channel wall.

2.2.2.1. Cross-linked enzyme crystals/aggregates (CLECs or

CLEAs) CLECs are the ordered form of CLEAs, which can either be nano- or microparticles with very high catalytic activity, because the crystals contain no support for immobilization, the whole particle is constituted of enzyme molecules (Fig. 4). There are numerous works in this field, an exhaustive review was published by Sheldon [132], however, only a few applications can be found in the field of microfluidics $[133,134]$. The cross-linked enzymes can form membranes on the inner surface of channels [135], unordered aggregates (CLEAs) [136] or CLECs $[133,134]$ that can be used in microreactors. However, only the last 2 examples from Conejero-Muriel et al. applying the CLECs are truly related to microchips $[133,134]$. They managed to create a microchip platform for protein crystallization by enzyme cross-linking and to implement enzymatic reactions [134]. Theoretically, this platform is applicable to any protein that can be crystallized; lipase [133], lysozyme and formamidase [134] were used as model proteins. The CLECs provided a reusable reactor with long shelf-life. It was also suggested that this platform can be used even as a sensing platform once coupled to a detection unit.
2.2.2.2. Magnetic particles The magnetic feature of particles provides additional advantages, like the recovery of expensive proteins or simplifying the purification of the mixture obtained after the enzymatic reaction. As can be seen in Fig. 3, these particles vary in size between nano- and microparticles, but the majority of them are microparticles.

The difficulty of creating packings in microfluidic chips was always a major concern. From practical experience, many researchers may know that substantial expertise and practice are needed to reproducibly create packings in microfluidic chips. This is partly due to the difficulty of retaining particles. In theory, the use of a properly sized and shaped physical obstacle is enough for retention due to the keystone effect, however, many parameters should be well controlled to properly retain the particle. This might be the motive behind the expanded use of magnetic particles to form microfluidic packings (Fig. 2). There are several examples to show their applicability, but problems regarding robustness are not fully solved, because magnets should be positioned accurately to get properly compressed packings without liquid streams.

Microparticles made of nonmagnetic substances (e.g. silica) can be made magnetic by coating the silica with ferrous material (e.g. $\mathrm{Fe}_{3} \mathrm{O}_{4}$ ). For example, fine (approx. $7 \mathrm{~nm}$ ) $\gamma-\mathrm{Fe}_{2} \mathrm{O}_{3}$ particles were deposited onto $5 \mu \mathrm{m}$ silica particles to make them magnetic [38].

Magnetic particles are widely utilized in proteomics related topics, there is ample literature available about immobilized tryptic microreactors applying magnetic particles as solid supports $[31-36,79,80]$. Their application for proteomic-related studies is covered later.

Magnetic particles can be retained conveniently with constant magnetic field; however, another possible utilization of their magnetic property is mixing. Mixing patterns can be generated with the application of oscillating magnetic fields. Such an experiment was conducted by Jussen et al. [41], who used this oscillating mixer to optimize the parameters of an enzymatic synthesis in a microchip IMER.
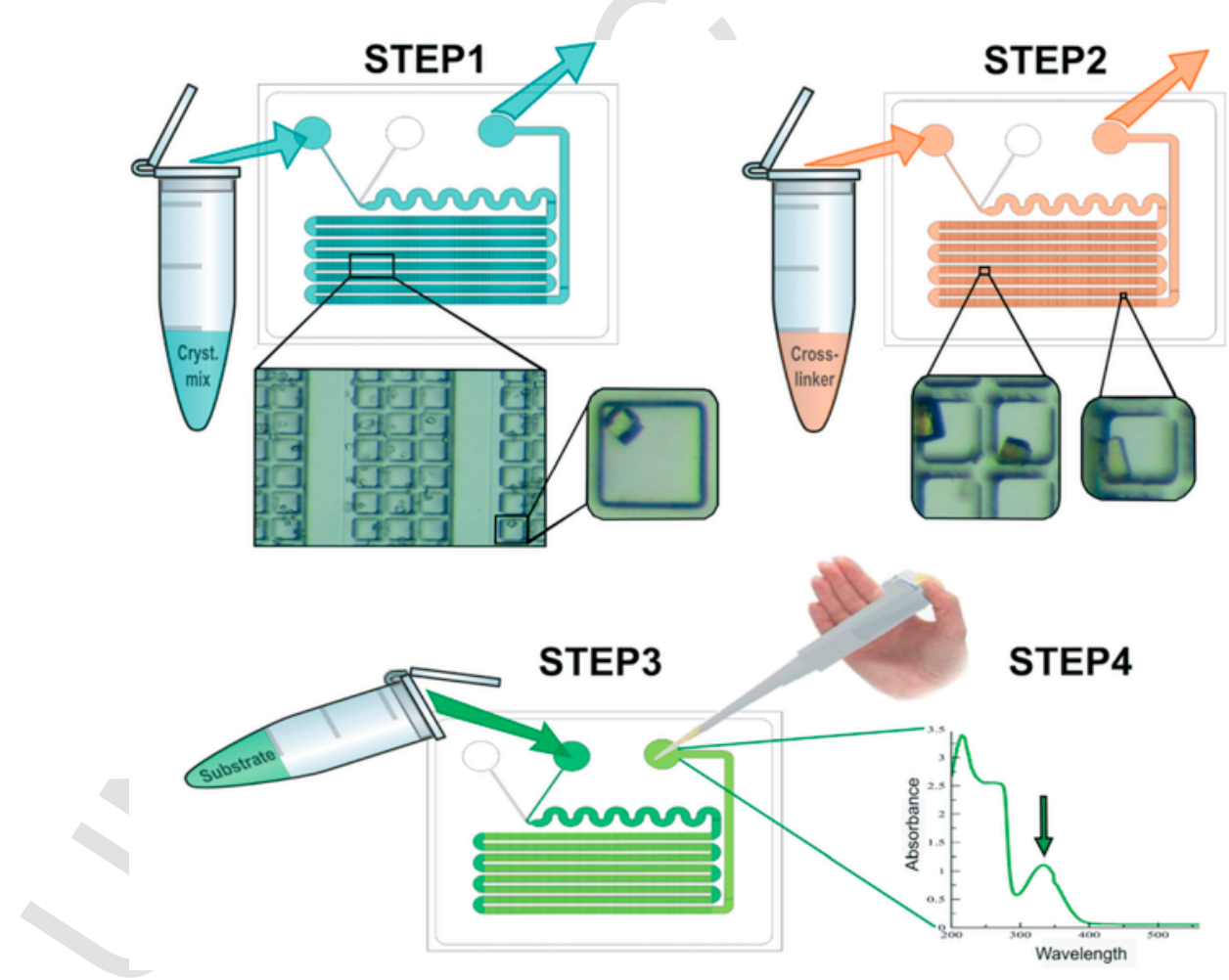

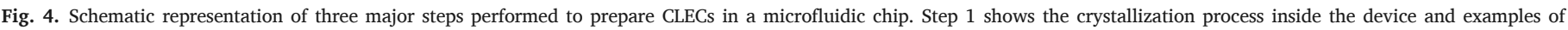

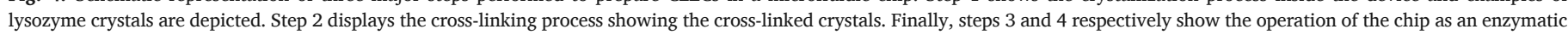
reactor and the final spectrophotometric detection for the product of the reaction. (Adapted from Ref. [134]). 
2.2.2.3. Silica beads For an analytical chemist, the simplest source of microparticles is the chromatographic packing materials (silica and its surface-modified versions). The high variety of surface modifications commercially available enables the application of almost any kind of immobilization strategy. Alternatively, different functionalities can be introduced by silanization. (3-aminopropyl)triethoxysilane (APTES) is most frequently used to introduce amino-functionalities.

The most general covalent coupling techniques will be discussed later, but silica allows not only covalent coupling, but even enzyme encapsulation into the particles. Spain et al. encapsulated nitrobenzene nitroreductase in silica particles with polyethyleneimine (PEI) mediator in a microcolumn and its activity was tested with three substrates: nitrobenzene, CB1954 (an anticancer prodrug) and nitrofurazone [51]. The same group reported the synthesis of a complex natural substance (2-aminophenoxazin-3-one) from a simple substrate (nitrobenzene) with metallic zinc, encapsulated hydroxylaminobenzene mutase and soybean peroxidase integrated into three different PDMS microchips and serially connected for continuous flow synthesis [45].
Agilent's commercial HPLC-chip system with two other polymeric chips were constructed and applied for glycoprotein deglycosylation, protein removal, glycan capture, LC separation and nano-ESI (to TOF-MS detection) by Bynum et al. [42]. In their study, PNGase F was immobilized covalently on $5 \mu \mathrm{m}$ silica particles previously silanized by (3-glycidyloxipropyl)trimethoxysilane.

2.2.2.4. Polystyrene beads $15.5 \mu \mathrm{m}$ PS beads were retained by a

7-12 $\mu \mathrm{m}$ deep weir in a PDMS microchip [68]. In this work, an enzymatic reactor was created, but more importantly, it was proven that the packed beads have an important role not only in providing increased surface area but also in mixing the laminar fluid streams. The mixing efficiency is dependent on the flow rate, bead size, channel dimensions and bead bed length [68] (Fig. 5). More works related to PS beads are to be mentioned in chapter 3 .

2.2.2.5. Agarose beads Another commercialized bead type is the cross-linked agarose bead containing various enzymes (e.g. trypsin, papain, pepsin) sold by Pierce (Rockford, IL). Lately, the size of such beads is not specified by the manufacturer, however, formerly it was $40-60$

(A)

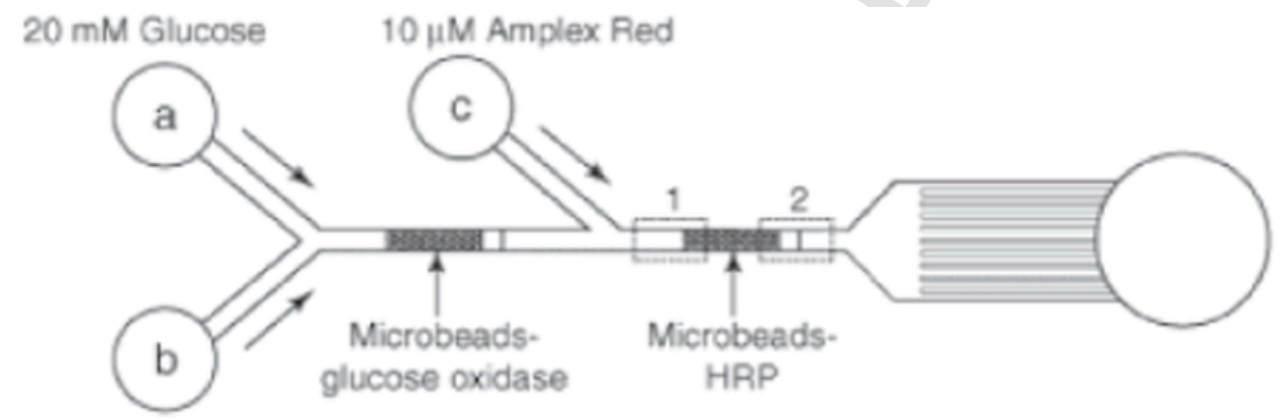

Tris-HCl butfer (pH 7.4)

(B)

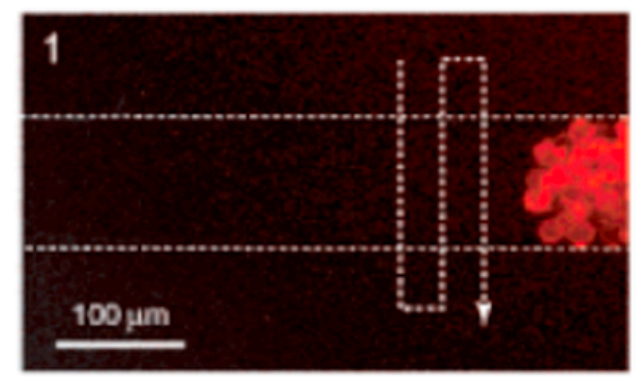

(D)

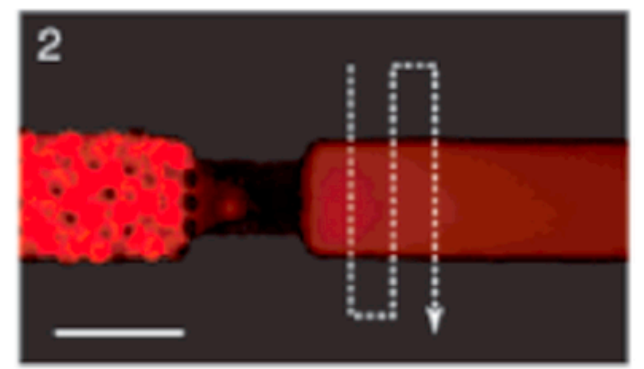

(C)

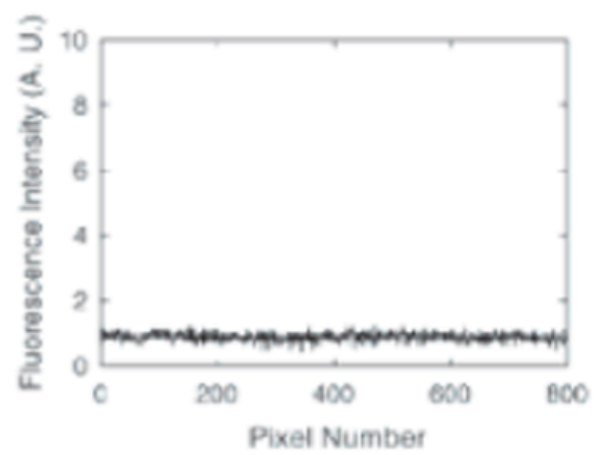

(E)

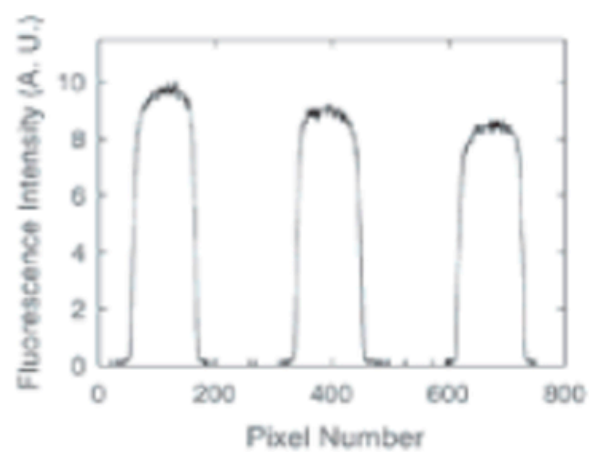

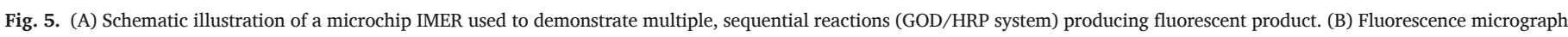

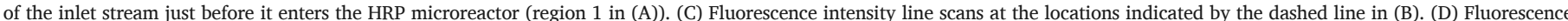

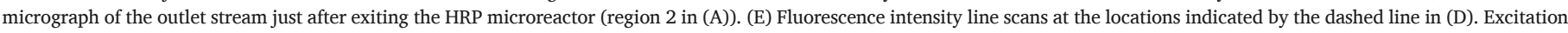
wavelength: $563 \mathrm{~nm}$; maximum emission wavelength: $587 \mathrm{~nm}$. The flow rate was $0.5 \mu \mathrm{L} / \mathrm{min}$ in all cases. (Adapted from Ref. [68]). 
[46,48] or 45-165 $\mu \mathrm{m}$ [137]. This size is considerably larger than most of the aforementioned microparticles, but they were originally manufactured to be used for in-gel digestion of proteins and the larger solid supports applied can be separated from the products more easily.

In spite of the original manufacturer's recommendations, several groups applied these commercial beads as packing material in integrated reaction chamber of microchips $[46,48,49]$. It is advantageous that the application of these larger particles results in lower backpressure, as high backpressure might have a negative influence on microchip robustness. The disadvantage of these beads is that the generally used microscopic channel (which is usually less than $100 \mu \mathrm{m}$ in width and height) should be enlarged, otherwise the particles would not fit into them. It is also questionable, if the porosity of the agarose beads can compensate the lower surface-to-volume ratio, which is the result of the larger particle size. All the following works cited apply the agarose particles in a packed bead format.

It was shown that protein digestion with immobilized trypsin on agarose can be accomplished in a simple reaction chamber, by using pressure [46] or electroosmotic flow [49] to transfer the protein sample through the packings. The integration of the beads into microchips enables protein digestion on agarose beads, solid phase extraction on reversed-phase beads), on-chip CE separation and electrospray MS analysis [48]. Liuni et al. integrated pepsin agarose particles (Sigma) into a microchip reactor format, which enabled electrospray ionization for MS coupling [47].

Non-commercial agarose beads were also presented in the literature. These were not produced with the immobilized enzymes by default, but the immobilization is very easy and straightforward. Ni-NTA agarose beads were used to capture a PikC hydroxylase enzyme in a PDMS-based microfluidic channel [138]. They used a small sol-gel frit at the end of the microchannel to withhold the particles. Immobilization was carried out by allowing PikC to flow through the Ni-NTA bead using centrifugal force, the enzyme was bonded through 6-His tag. The immobilized PikC was used for the hydroxylation of the macrolide YC-17 in the presence of ferredoxin-NADP ${ }^{+}$reductase, ferredoxin and NADPH.

2.2.2.6. Poly(styrene-divinylbenzene) (PSDVB) particles Another type of widely-used, commercial particles with immobilized trypsin is Poroszyme ${ }^{\circledR}$ beads [139]. These are $20 \mu \mathrm{m}$ beads made from cross-linked PSDVB with immobilized trypsin. These particles contain large pores that allow solutes to perfuse through the particles and small pores that make diffusion possible. Poroszyme ${ }^{\circledR}$ is widely used in bulk and cartridge format, but only a few applications can be found in on-line systems [140] and even fewer, if any of the works were made in microchip format.

2.2.2.7. Glass beads Glass beads possess a relatively larger diameter, but the particles can either be porous or nonporous. Porous glass beads are usually referred to as controlled pore glass (CPG), which can be used for enzyme immobilization [52,55,56]. Their 120-200 mesh size (approx. 80-120 $\mu \mathrm{m}$ ) is somewhat larger than the smaller micro- or nanoparticles, however, its porous character provides a S/V ratio unexpectedly high considering its particle size. The pore size of CPG must be well-selected, because only the smaller enzymes can be immobilized in smaller pores, but the smaller pores are those that provide the higher specific surface area essential in these heterogeneous reactions.

The immobilization of alkaline phosphatase, xanthine oxidase (XOD) [52] and sucrose phosphorylase [56] was carried out with the use of CPG for the microfluidic assays of p-nitrophenyl phosphate and hypoxanthine and for the production of 2-O-( $\alpha$-D-glycopyranosyl)-sn-glycerol, respectively. These works applied 3 different immobilization techniques for the different enzymes, which proves that $i$, immobilization techniques affect enzymatic activity, different enzymes may have different responses on the immobilization reaction (i.e. if the covalent attachment occurs in the enzyme's active site) and ii, CPG is a very versatile tool for enzyme immobilization, many surface modifications can be carried out on its surface.

Nonporous glass beads with considerably large dimensions (50 and $70 \mu \mathrm{m}$ ) were used for glucose sensing by amperometry and fluorescence $[53,54]$. As mentioned previously, with larger bead size comes smaller specific surface area, which is disadvantageous in these heterogeneous systems, resulting in less bound enzyme and fewer encounters between enzyme and substrate. However, a major advantage of this system is the lack of (or only negligible) backpressure, which is usually formed when smaller particles are packed. High backpressure can cause problems in microfluidic chips, as it decreases their robustness.

\subsubsection{Millimeter-scale particles}

In the past decades, miniaturization has become a rapidly developing trend, particularly in the manufacturing of electronic devices. Miniaturization in analytical chemistry is also a growing field, aiming at the integration of numerous analytical processes into a small microfluidic chip. However, there are a few cases when scaling these devices up is a logical solution for problems when larger dimensions are required (e.g. synthesis). This field is only loosely related to microfluidics, thus only a short description of applicable particles with millimeter-scale sizes is provided.

Millimeter-sized particles $(0.5-10 \mathrm{~mm})$ can be obtained when polyvinyl alcohol (PVA) (LentiKats ${ }^{\circledR}$ ) [141] or polyelectrolytes [74] are gelled, in which enzymes can be encapsulated.

2.2.3.1. Lentikats ${ }^{\circledR}$ Lentikats ${ }^{\circledR}$ are the largest particles involved in this review with approx. $4 \mathrm{~mm}$ diameter, therefore they cannot be integrated into a 'classical' microfluidic chip, only into its upscaled version. The particles are made of polyvinyl alcohol into a lens shape, immobilization of many enzymes including cyclopentanone monooxygenase [75] and $\omega$-transaminase [71] were conducted by encapsulation in these particles. Due to its larger dimensions, the $\mathrm{S} / \mathrm{V}$ ratio is not as high as in a microfluidic reactor with smaller particles, but their porous character can somewhat amend this drawback.

2.2.3.2. Polyelectrolyte capsules Polyelectrolyte capsules are formed by the complexation of sodium-alginate, cellulose sulfate and poly(methylene-co-guanidine) [74]. Although there are several examples in which enzymes are encapsulated in alginate [73], only a few works combine the alginate encapsulation and microfluidics, in which case whole cells are encapsulated in the microchip [142,143].

2.2.3.3. Novozyme 435 Novozyme 435 (also known as lipase acrylic resin from Candida antarctica) particles are macroporous polyacrylic resin beads with a diameter of $0.3-0.9 \mathrm{~mm}$, containing physically immobilized lipase by the manufacturer. The particle size of Novozyme 435 suggests that the channels/capillaries used are considerably larger ( $\mathrm{d}=1.65 \mathrm{~mm}$ [59]) than the usual microfluidic chip channels, which might be advantageous, as these particles can be used for synthetic reactions. Isoamyl alcohol acylation $[60,72]$, butyl butyrate $[61,62]$ and caffeic acid phenethyl ester synthesis [63], polymerization reaction of $\varepsilon$-caprolactone to polycaprolactone [64], continuous esterification of organic acids with methanol [59] were all carried out in similar, lipase immobilized microreactors. The typical dimensions of such reactors are: $0.45-1 \mathrm{~mm}$ (height), $1-50 \mathrm{~mm}$ (width) and 75-260 mm (length) for channels or 1-5 mm (diameter) and 30-100 mm (length) for capillaries. The mass of the packed particles were $50-105 \mathrm{mg}$, with only one exception with 635-660 mg [62] packed particle (the latter reactor had the largest internal volume).

\subsection{Immobilization of enzymes}

For the immobilization of enzymes onto solid materials, several methods have been shown in the last decades (Fig. 6). These immobi- 


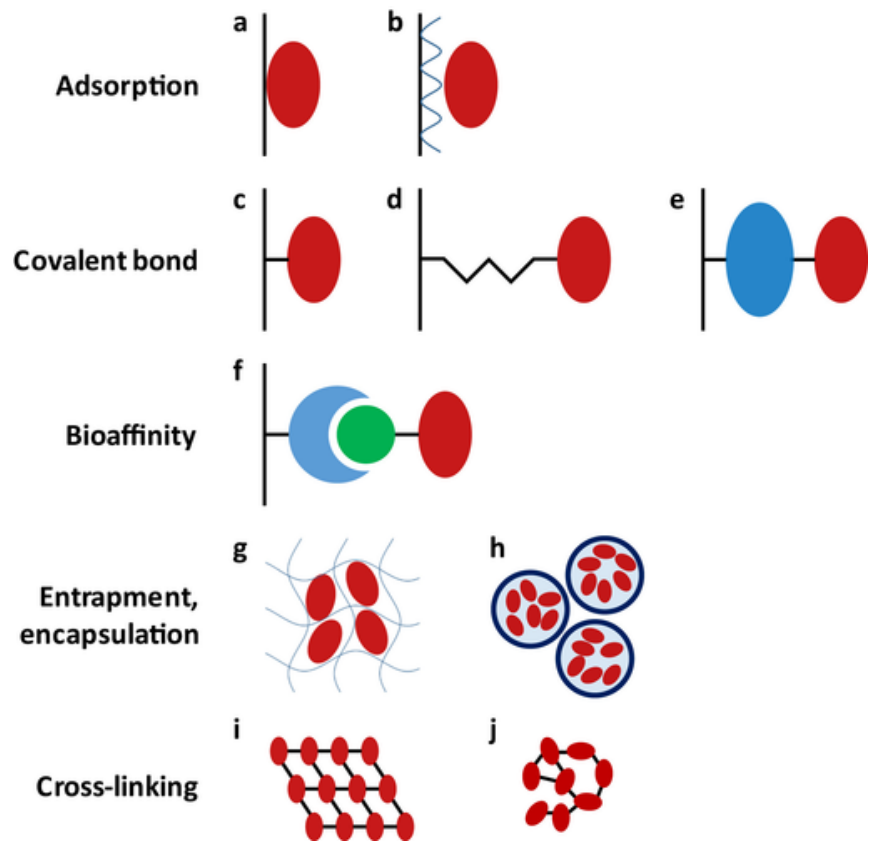

Fig. 6. Schematic representation of different enzyme immobilization strategies: (a) direct adsorption, (b) LBL adsorption; covalent coupling (c) directly (e.g. EDC/NHS coupling), (d) through a short spacer (e.g. glutaraldehyde), (e) through a large spacer (e.g. BSA); (f) coupling by bioaffinity interaction (e.g. avidin-biotin interaction); (g) entrapment into a gel matrix, (h) encapsulation into polyelectrolyte capsules; cross-linking to form (i) ordered crystals (CLECs) or (j) unordered aggregates (CLEAs).

lization strategies were reviewed $[97,144,145]$, therefore only a short description is provided herein.

The main enzyme immobilization strategies are adsorption, covalent bond, bioaffinity linkage, encapsulation and enzyme cross-linking (see Table 2 for references). In some cases, the application of a spacer is mentioned as another class, however, spacers are used to provide better enzyme stability and they do not affect the immobilization strategy. For example, LBL adsorption includes the adsorption of several layers before the final enzyme layer is adsorbed. These layers are usually not called spacers, yet they prevent the direct contact between the enzyme and the solid surface. Similarly, avidin and biotin are also spacers when bioaffinity interaction is applied, and several spacers from the smaller glutaraldehyde to the large bovine serum albumin (BSA) can be used for covalent coupling.

The simplest technique for immobilization is adsorption. It can be accomplished by simply making a contact between the immobilization surface and the enzyme solution. Adsorption occurs based on either hydrophobic or electrostatic interactions. The use of $Z_{\text {basic2 }}$, a positively charged small protein (spacer), enables the adsorption of a negatively charged enzyme onto a negatively charged surface [56,146]. Adsorption is especially preferred if the surface lacks reactive functional groups, when covalent coupling would be complicated. The simplicity of the technique might be suppressed by its major drawback, which is the decrease in enzyme activity. When the enzyme becomes immobilized, it must come into contact with the surface (if there is no spacer) and interact with it. These interactions tend to alter the conformation of the enzyme, as more and more interacting side chains get located at the interface. Finally, the enzyme spreads on the surface and the distorted conformation will possess lower or no activity.

Covalent coupling is the most widely used strategy, offering a more stable surface than adsorption. The reactions used are necessarily more complex, but the majority of the works (Table 2) apply glutaraldehyde coupling of two amine groups (thus forming a Schiff base, which can be further reduced to an amine) or carbodiimide activation of a carboxyl group, which is further reacted with an amine (thus forming amide bond). The required reagents are low-cost and the reactions are straightforward. Immobilized enzymatic reactors obtained this way might have outstanding stability (typically several months without activity decrease).

Bioaffinity interaction is a very specific technique, requiring the derivatization of the enzyme and the surface. Enzymes are to be firstly biotinylated and the surface is to be coated with streptavidin or avidin. The interaction is formed between these functionalities. Some producers offer precoated particles, like streptavidin-coated microspheres from Bangs Laboratories, Inc., which is a popular material of choice $[69,70,147]$. The specific character of bioaffinity offers prolonged enzyme stability and excellent control of the immobilization. Biotin and avidin are also spacers preventing enzyme spreading, however, the high price of the derivatization agents makes this technique the most expensive. Enzyme immobilization through 6-His tag (to Ni- or Co-ion containing resins) can also be listed into bioaffinity interactions $[41,138]$.

Entrapment of a substance means an immobilization, when the substance gets trapped/surrounded by an insoluble matrix, which is mostly a gel-like structure. If this gel-like matrix fills the whole channel, in which particles or enzymes [148] can be entrapped, monoliths are obtained. Entrapment can also be carried out if the insoluble matrix does not fill the whole channel, but located near the wall, as a coating. In this case, entrapped enzymes or particles can be obtained, as well, but they are not called monoliths. In this review, we only take the entrapped particles into consideration, which were mostly zeolite nanoparticles entrapped into sol-gels, and were described in Section 2.2.1.

Enzyme cross-linking can result in different products: membranes, aggregates (CLEAs) or crystals (CLECs). There is no need for particles or immobilization surfaces, the crystallized enzyme possesses outstanding activity. The reaction itself - glutaraldehyde cross-linking of enzyme molecules - is simple, but the reaction circumstances of crystallization need to be carefully optimized, therefore much experience is needed to produce enzyme crystals.

\subsection{Coupling with detectors}

For microfluidic devices, many different detection methods have been applied although the accurate and sensitive detection of the minute volumes of analytes achievable in microchips generally still counts as a great challenge. The main requirements for the optimal detector applied to microchips are the reduced diffusion length between the chip and the detection cell and the ability to operate only a few microliters or less sample. Obviously, most detection systems applied with microchips can be used with microchip IMERs. Based on the arrangement of the microchip and the detector, on-chip and off-chip detection options should be distinguished. In several cases when the detector cannot be miniaturized to the scale of the microchips (e.g. mass spectrometers, NMR) only off-chip arrangements can be accomplished. However, several optical and electrochemical detectors can be effectively integrated into the chip and in some cases (e.g. contactless conductivity detectors, MALDI) the microchip can be reversibly placed onto the detector plate. Two main trends can be seen in the research on microchip IMERs: completely integrated detection in a chip (on-chip) and high efficiency MS detection on-line connected with a chip (off-chip). There are several reviews published about the applicability of electrochemical [149], optical [150] and mass spectrometric [151] detection methods.

The most effective and popular on-chip sensing method is the fluorescence - mainly laser-induced fluorescence (LIF) - detection, because of the high sensitivity, the need of minimal analyte amount and its ease of implementation [152]. In LIF detection the requirement for a fluorophore group in the analyte molecule is relatively easy to satisfy since 
Table 2

Comparison of immobilized enzymatic reactors.

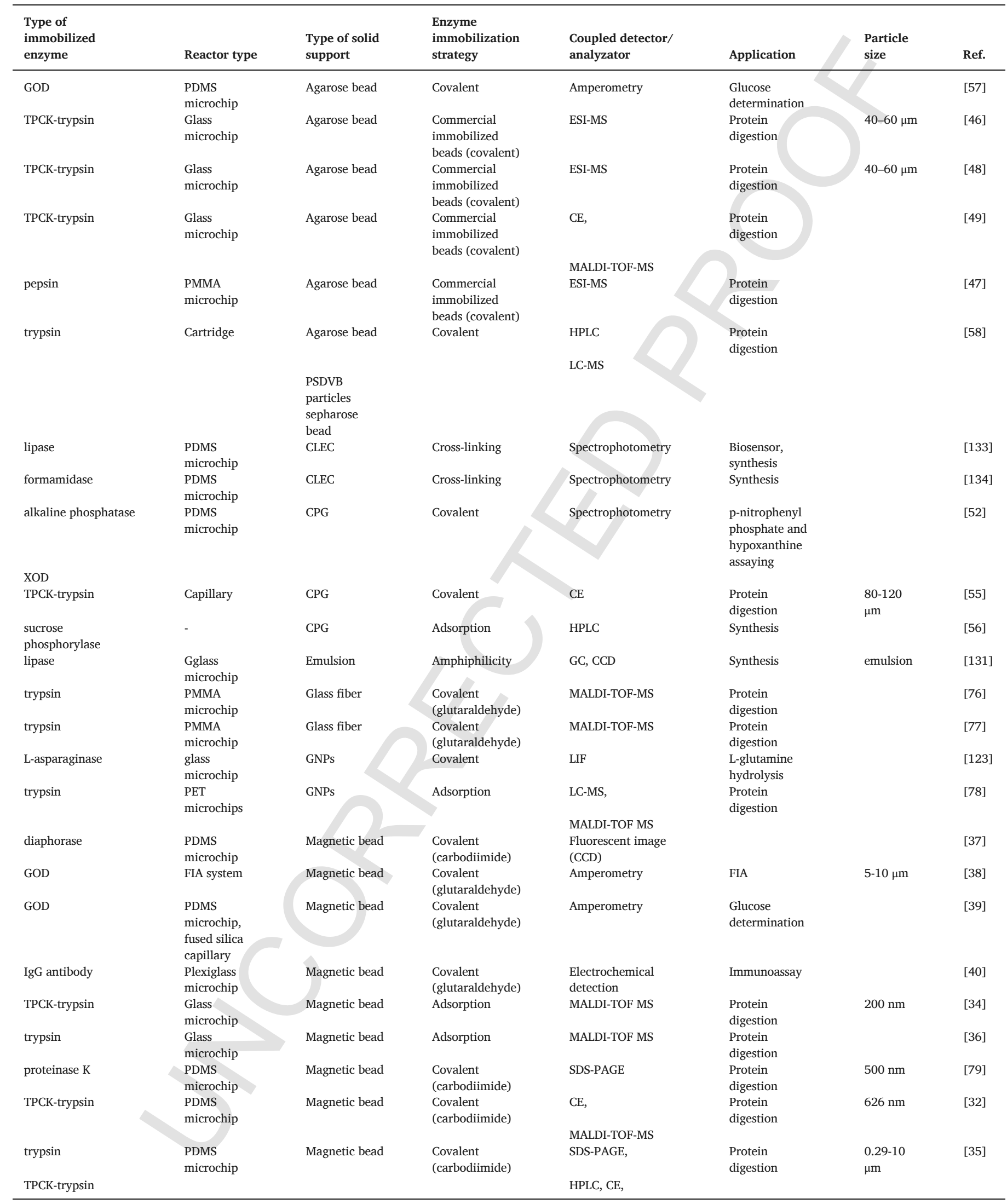




\begin{tabular}{|c|c|c|c|c|c|c|c|}
\hline & $\begin{array}{l}\text { MALDI-FT- } \\
\text { ICR-MS }\end{array}$ & & & & & & \\
\hline trypsin & $\begin{array}{l}\text { PDMS } \\
\text { microchip }\end{array}$ & Magnetic bead & $\begin{array}{l}\text { Covalent } \\
\text { (carbodiimide) }\end{array}$ & ESI-MS & $\begin{array}{l}\text { Protein } \\
\text { digestion }\end{array}$ & $500 \mathrm{~nm}$ & [31] \\
\hline TPCK-trypsin & capillary & Magnetic bead & $\begin{array}{l}\text { Covalent } \\
\text { (carbodiimide) }\end{array}$ & CE-MS & $\begin{array}{l}\text { Protein } \\
\text { digestion }\end{array}$ & $100 \mathrm{~nm}$ & [168] \\
\hline
\end{tabular}


Table 2 (Continued)

\begin{tabular}{|c|c|c|c|c|c|c|c|}
\hline $\begin{array}{l}\text { Type of } \\
\text { immobilized } \\
\text { enzyme }\end{array}$ & Reactor type & $\begin{array}{l}\text { Type of solid } \\
\text { support }\end{array}$ & $\begin{array}{l}\text { Enzyme } \\
\text { immobilization } \\
\text { strategy }\end{array}$ & $\begin{array}{l}\text { Coupled detector/ } \\
\text { analyzator }\end{array}$ & Application & $\begin{array}{l}\text { Particle } \\
\text { size }\end{array}$ & Ref. \\
\hline TPCK-trypsin & $\begin{array}{l}\text { Glass } \\
\text { microchip }\end{array}$ & Magnetic bead & $\begin{array}{l}\text { Covalent } \\
\text { (glutaraldehyde) }\end{array}$ & MALDI-TOF MS & $\begin{array}{l}\text { Protein } \\
\text { digestion }\end{array}$ & $300 \mathrm{~nm}$ & {$[80]$} \\
\hline TPCK-trypsin & $\begin{array}{l}\text { Glass } \\
\text { microchip }\end{array}$ & Magnetic bead & $\begin{array}{l}\text { Covalent } \\
\text { (glutaraldehyde) }\end{array}$ & MALDI-TOF MS & $\begin{array}{l}\text { Protein } \\
\text { digestion }\end{array}$ & $50 \mathrm{~nm}$ & {$[33]$} \\
\hline $\begin{array}{l}\text { benzoylformate } \\
\text { decarboxylase }\end{array}$ & $\begin{array}{l}\text { Glass } \\
\text { microchip }\end{array}$ & Magnetic bead & His-tag & HPLC & Synthesis & & [41] \\
\hline acetylcholinesterase & $\begin{array}{l}\text { PDMS } \\
\text { microchip }\end{array}$ & $\begin{array}{l}\text { Magnetic } \\
\text { nanocomposite }\end{array}$ & Adsorption & Amperometry & $\begin{array}{l}\text { Pesticide } \\
\text { determination }\end{array}$ & & {$[83]$} \\
\hline trypsin & $\begin{array}{l}\text { PMMA } \\
\text { microchip }\end{array}$ & Nanozeolite & Adsorption & MALDI-TOF MS & $\begin{array}{l}\text { Protein } \\
\text { digestion }\end{array}$ & & {$[81]$} \\
\hline trypsin & $\begin{array}{l}\text { PMMA } \\
\text { microchip }\end{array}$ & Nanozeolite & Encapsulation & MALDI-TOF MS & $\begin{array}{l}\text { Protein } \\
\text { digestion }\end{array}$ & & {$[82]$} \\
\hline PikC hydroxylase & $\begin{array}{l}\text { PDMS } \\
\text { microchip }\end{array}$ & $\begin{array}{l}\text { Ni-NTA } \\
\text { agarose beads }\end{array}$ & His-tag & Spectrophotometry & $\begin{array}{l}\text { Functional } \\
\text { group }\end{array}$ & & [138] \\
\hline GOD & $\begin{array}{l}\text { Pyrex wafer } \\
\text { chip }\end{array}$ & $\begin{array}{l}\text { Nonporous } \\
\text { glass bead }\end{array}$ & $\begin{array}{l}\text { Covalent } \\
\text { (glutaraldehyde) }\end{array}$ & Amperometry & $\begin{array}{l}\text { introduction } \\
\text { Glucose } \\
\text { determination }\end{array}$ & $50 \mu \mathrm{m}$ & {$[53]$} \\
\hline GOD & $\begin{array}{l}\text { PDMS } \\
\text { microchip }\end{array}$ & $\begin{array}{l}\text { Nonporous } \\
\text { glass bead }\end{array}$ & $\begin{array}{l}\text { Covalent } \\
\text { (glutaraldehyde) }\end{array}$ & $\begin{array}{l}\text { Fluorescent image } \\
\text { (CCD) }\end{array}$ & $\begin{array}{l}\text { Glucose } \\
\text { determination }\end{array}$ & $70 \mu \mathrm{m}$ & {$[54]$} \\
\hline lipase & $\begin{array}{l}\text { Packed bed } \\
\text { reactor }\end{array}$ & $\begin{array}{l}\text { Polyacrylic } \\
\text { resin beads }\end{array}$ & Adsorption & GPC & Polymerization & & {$[64]$} \\
\hline lipase & $\begin{array}{l}\text { Packed bed } \\
\text { capillary } \\
\text { reactor }\end{array}$ & $\begin{array}{l}\text { Polyacrylic } \\
\text { resin beads }\end{array}$ & Adsorption & GC & Synthesis & & [59] \\
\hline lipase & $\begin{array}{l}\text { Packed bed } \\
\text { reactor }\end{array}$ & $\begin{array}{l}\text { polyacrylic } \\
\text { resin beads }\end{array}$ & Adsorption & GC & Synthesis & & {$[60]$} \\
\hline \multirow[t]{2}{*}{ lipase } & H-Cube ${ }^{\mathrm{TM}}$ & $\begin{array}{l}\text { Polyacrylic } \\
\text { resin beads }\end{array}$ & Adsorption & GC & Synthesis & & {$[72]$} \\
\hline & $\mathrm{X}-$ Cube $^{\mathrm{TM}}$ & & & & & & \\
\hline lipase & $\begin{array}{l}\text { Packed bed } \\
\text { reactor }\end{array}$ & $\begin{array}{l}\text { Polyacrylic } \\
\text { resin beads }\end{array}$ & Adsorption & GC & Synthesis & & {$[61]$} \\
\hline lipase & $\begin{array}{l}\text { Packed bed } \\
\text { reactor }\end{array}$ & $\begin{array}{l}\text { Polyacrylic } \\
\text { resin beads }\end{array}$ & Adsorption & GC & Synthesis & & {$[62]$} \\
\hline lipase & $\begin{array}{l}\text { Packed bed } \\
\text { reactor }\end{array}$ & $\begin{array}{l}\text { Polyacrylic } \\
\text { resin beads }\end{array}$ & Adsorption & LC-MS, NMR, HPLC & Synthesis & & {$[63]$} \\
\hline GOD & Batch & $\begin{array}{l}\text { Polyelectrolyte } \\
\text { capsules }\end{array}$ & Encapsulation & spectrophotometry & $\begin{array}{l}\text { Functional } \\
\text { group } \\
\text { conversion }\end{array}$ & & [73] \\
\hline $\begin{array}{l}\text { cis-epoxysuccinate } \\
\text { hydrolase cells }\end{array}$ & Batch & $\begin{array}{l}\text { Polyelectrolyte } \\
\text { capsules }\end{array}$ & Encapsulation & $\begin{array}{l}\text { HPLC, ESI-MS, } \\
\text { optical rotation }\end{array}$ & Hydrolysis & & [74] \\
\hline GOD & $\begin{array}{l}\text { PDMS } \\
\text { microchip }\end{array}$ & PS beads & Bioaffinity & $\begin{array}{l}\text { fluorescent image } \\
\text { (CCD) }\end{array}$ & $\begin{array}{l}\text { Glucose } \\
\text { determination }\end{array}$ & $15.5 \mu \mathrm{m}$ & {$[68]$} \\
\hline \multicolumn{8}{|l|}{ HRP } \\
\hline GOD & $\begin{array}{l}\text { PDMS } \\
\text { microchip }\end{array}$ & PS beads & Bioaffinity & $\begin{array}{l}\text { fluorescent image } \\
\text { (CCD) }\end{array}$ & $\begin{array}{l}\text { Glucose } \\
\text { determination }\end{array}$ & & {$[70]$} \\
\hline \multicolumn{8}{|l|}{ HRP } \\
\hline IgA antibody & $\begin{array}{l}\text { Glass } \\
\text { microchip }\end{array}$ & PS beads & Adsorption & $\begin{array}{l}\text { Laser-induced } \\
\text { thermal lens } \\
\text { microscopy }\end{array}$ & Immunoassay & & [65] \\
\hline anti-CEA antibody & $\begin{array}{l}\text { Glass } \\
\text { microchip }\end{array}$ & PS beads & Adsorption & $\begin{array}{l}\text { Laser-induced } \\
\text { thermal lens } \\
\text { microscopy }\end{array}$ & Immunoassay & & [66] \\
\hline $\begin{array}{l}\text { anti-interferon } \\
\text { antibody }\end{array}$ & $\begin{array}{l}\text { Glass } \\
\text { microchip }\end{array}$ & PS beads & Adsorption & $\begin{array}{l}\text { Laser-induced } \\
\text { thermal lens } \\
\text { microscopy }\end{array}$ & Immunoassay & & {$[67]$} \\
\hline$\beta$-galactosidase & $\begin{array}{l}\text { PDMS } \\
\text { microchip }\end{array}$ & PS beads & Bioaffinity & $\begin{array}{l}\text { Fluorescent image } \\
\text { (CCD) }\end{array}$ & $\begin{array}{l}\text { Lactose } \\
\text { determination }\end{array}$ & & [69] \\
\hline \multicolumn{8}{|l|}{ GOD } \\
\hline $\begin{array}{l}\text { HRP } \\
\text { trypsin }\end{array}$ & $\begin{array}{l}\text { Commercial } \\
\text { cartridge }\end{array}$ & $\begin{array}{l}\text { PSDVB } \\
\text { particles }\end{array}$ & $\begin{array}{l}\text { Commercial } \\
\text { immobilized } \\
\text { beads (covalent) }\end{array}$ & SEC & $\begin{array}{l}\text { Protein } \\
\text { digestion }\end{array}$ & & [140] \\
\hline$\omega$-transaminase & $\begin{array}{l}\text { Packed bed } \\
\text { reactor }\end{array}$ & PVA particles & Encapsulation & HPLC, GC & Synthesis & & {$[71]$} \\
\hline \multirow[t]{2}{*}{$\begin{array}{l}\text { cyclopentanone } \\
\text { monooxygenase cells }\end{array}$} & batch & $\begin{array}{l}\text { PVA particles, } \\
\text { polyelectrolyte } \\
\text { capsules }\end{array}$ & Encapsulation & GC & $\begin{array}{l}\text { Functional } \\
\text { group } \\
\text { conversion }\end{array}$ & $3.65 \mathrm{~mm}$ & {$[75]$} \\
\hline & & & & & & $0.82 \mathrm{~mm}$ & \\
\hline
\end{tabular}




\begin{tabular}{|c|c|c|c|c|c|c|c|}
\hline $\begin{array}{l}\text { nitrobenzene } \\
\text { nitroreductase }\end{array}$ & Microcolumn & Silica & Encapsulation & HPLC & $\begin{array}{l}\text { Functional } \\
\text { group } \\
\text { conversion }\end{array}$ & & [51] \\
\hline PNGase F & $\begin{array}{l}\text { Commercial } \\
\text { microchip } \\
\text { polyimide } \\
\text { microchip }\end{array}$ & Silica & Covalent & LC-MS & Glycan analysis & $5 \mu \mathrm{m}$ & [42] \\
\hline
\end{tabular}

Table 2 (Continued)

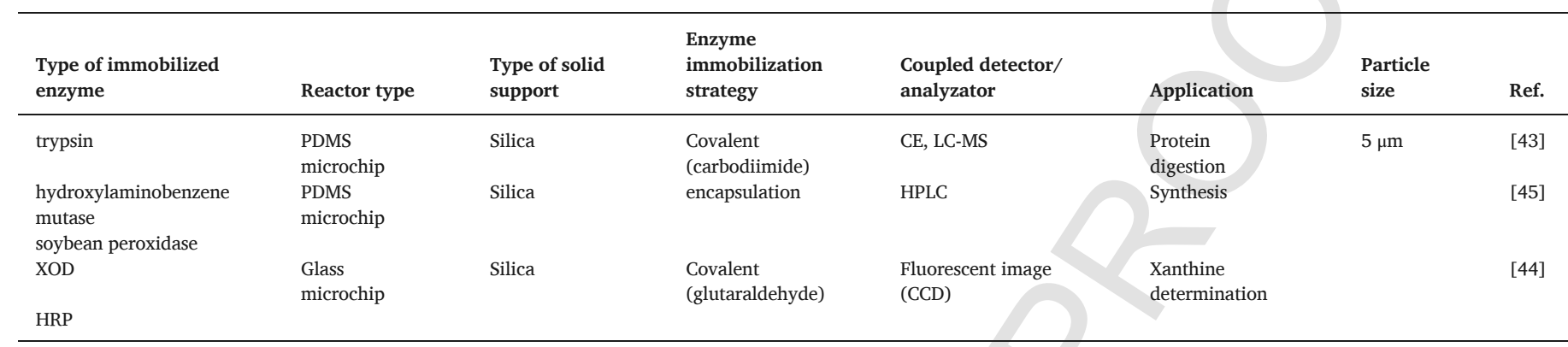

a large variety of fluorescent dyes for labelling biomolecules are available and widely used. In addition, the most popular commercialized microfluidic systems use LIF detection (e.g. Bioanalyzer ${ }^{\circledR}$ from Agilent, Labchip ${ }^{\circledR}$ from PerkinElmer).

One of the most widely applied detection methods of analytical chemistry is UV absorption spectrometry, which can be miniaturized, but unfortunately poor detection sensitivity can be achieved in microchips due to the very short optical path length. The spectrometric detection used for microchip IMERs incorporates either optical fibers [153] or waveguides [154] integrated into the chip. Besides UV absorption, other optical spectrometric detection methods like IR or Raman were also used for microchip IMERs [155]. The integration of electrochemical detectors into chips was also intensively studied in research laboratories, but the integration and operation of these detectors need significant microfabrication expertise [151]. Even large instruments, like NMR was hyphenated to microchip IMER through a miniaturized NMR coil and applied it for measuring reaction kinetics [156]. The simplest and most comfortable way of hyphenation is when the microchip is placed onto the surface of a sensor, but there is no direct contact between the fluid and the sensor. This is the case with capacitively coupled contactless conductivity detectors, where the microchip can be reversibly placed or removed onto/from the detector and the detection site on the chip can be varied freely [157]. Also the traditional separation methods (HPLC, UHPLC, GC, CE) were on-line coupled with microchip IMERs, as samples were transferred from the microreactor to the chromatographic units via proper microsyringes and valves [158]. In these systems, a high speed and efficient enzymatic reaction occurred typically in the microchip and the separated components were transferred into the mass spectrometer.

The combination of microchip IMERs with mass spectrometry is particularly popular because in these systems high-throughput analysis can be achieved by which the proteomic studies can largely be accelerated. In most chip IMER-MS systems, the chips are used for sample pretreatment including analyte (protein) digestion, preconcentration of analyte, removal of matrix materials. A number of strategies for coupling on-chip separation and digestion techniques with MS analysis have been developed $[31,150,159,160]$. The efficient hyphenation of microchips with mass spectrometers is the major target of recent microfluidic research. Electrospray ionization (ESI) and matrix-assisted laser desorption/ionization (MALDI) are the two most often applied ionization techniques for proteomics, and since the IMERs are often used as protein digestion reactors, those are typically used for microchip IMERs. The ESI interface utilizes either pressure driven (Fig. 7)
[31,161] or electric field driven (electroosmotic) [162,163] flow. Since applied flow rates in IMERs do not exceed the $\mu \mathrm{L} / \mathrm{min}$ range, nano-ESI is the most often used interface towards MS. Generally, the ESI needle is a fused silica tip positioned at the end of the channel system on the chip. In the case of MALDI-MS, the hyphenation with microchips is accomplished typically by depositing the effluents of the chip onto the MALDI target plate [164,165].

\section{Applications of particle based IMERs}

\subsection{Protein digestion}

Accelerating protein digestion is probably the hottest topic in microchip IMER technology, which is notably attributed to the relevance of this field. Proteomics is a rapidly developing field of study, aiming to characterize the whole protein content of cells in different organizations [166]. The method behind protein identifications - namely peptide mass mapping/fingerprinting - includes protein digestion, which is the rate determining step of the analysis. Although the concept of shotgun proteomics provided a boost in accelerating the whole analytical process [167], time-consuming protein digestion is still involved. This is due to the necessity to apply trypsin in low concentration (protein: trypsin $=20-100: 1$ ) in free form, to hinder its autolysis. Typical digestion times range from 2 to $30 \mathrm{~h}$. When trypsin is immobilized on a solid support, it cannot encounter another (immobilized) trypsin molecule, thus autolysis is prevented. This is the extra motive - apart from the small sample requirement, ease of separation from product and reusability - behind using immobilized proteolytic microreactors.

In these protein digestion systems, proteolytic enzymes (usually trypsin) are immobilized on particles integrated into microfluidic chips. Protein digestion occurs in the chip, digestion times are in the range of $10 \mathrm{~s}$ to $10 \mathrm{~min}$. The chip can be coupled online to the separation/detection unit (e.g. MS), or else the effluent sample is collected for further (offline) analysis (Fig. 8). Table 2. contains the detection techniques applied for the analysis of the peptide products.

For proteomic studies, magnetic particles [31-36,79,80,168] and agarose particles $[46-49,58]$ are the preferred types of solid supports, because packings can be formed conveniently from magnetic particles and because trypsin coated agarose beads are commercially available. An elegant microfluidic device was shown by Harrison's group [47] as they made multifunctional protein processing possible through two serially connected channels. The channels were packed with agarose 

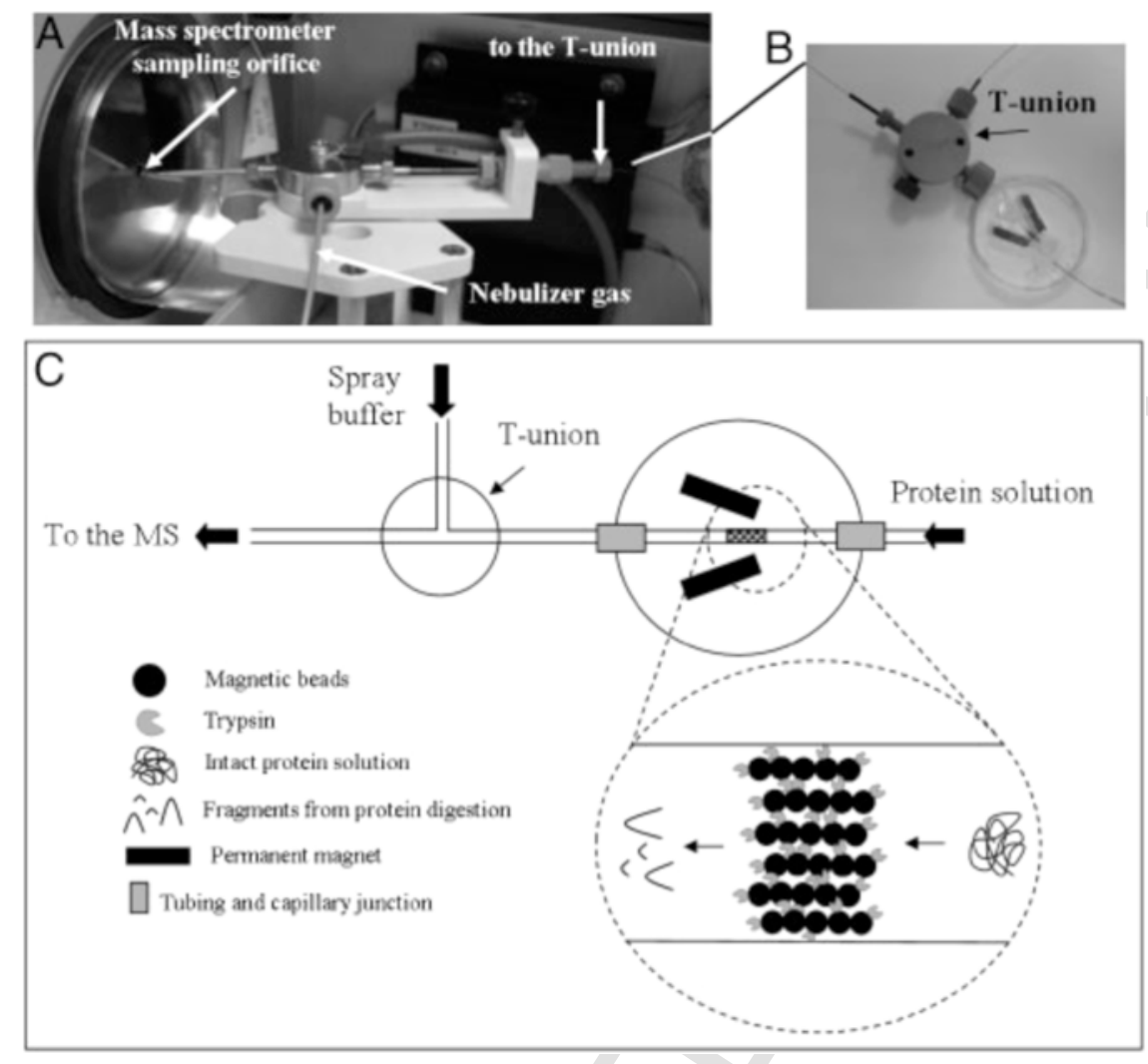

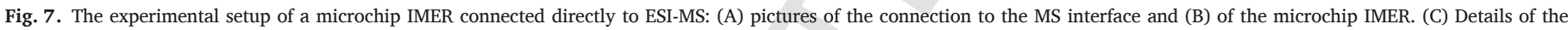
microchip IMER with magnets and a T-union for coupling with the ESI interface. (Adapted from Ref. [31]).

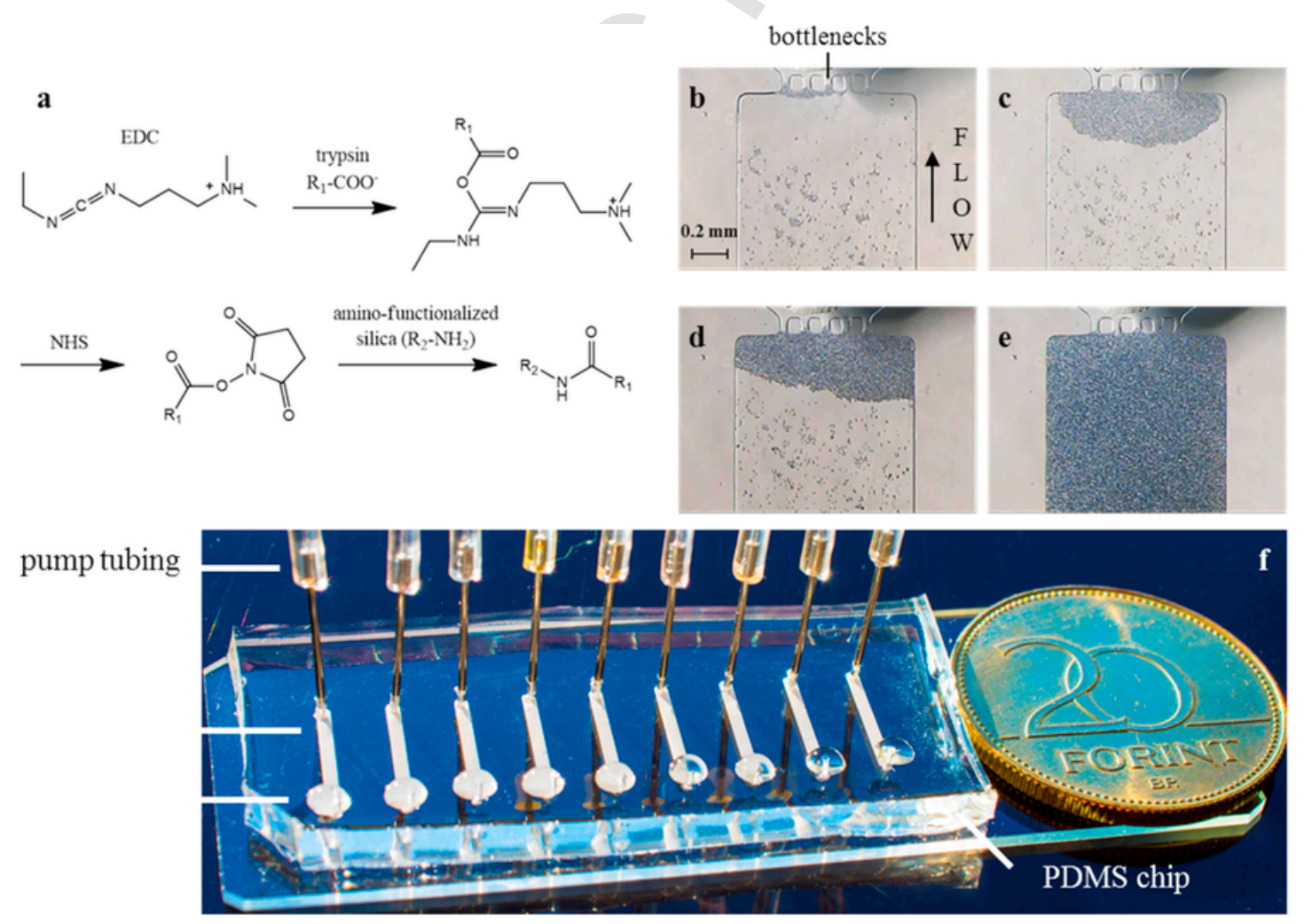

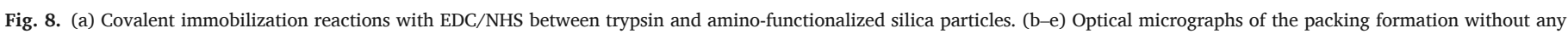

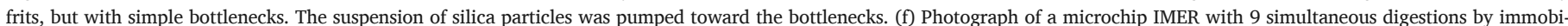
lized trypsin. (Adapted from Ref. [43]). 
beads containing immobilized trypsin and reversed-phase beads to create an enzyme reactor and an SPE microcolumn, respectively (Fig. 9). Magnetic particles - either magnetic themselves (e.g. magnetite) or magnetically coated particles - with sizes typically in the range of $50 \mathrm{~nm}$ to $5 \mu \mathrm{m}$ are packed into the channel of a PDMS or glass microfluidic chip with the help of constant magnetic field generated close to the channel. In each case, trypsin is immobilized covalently (with carbodiimide activation or glutaraldehyde coupling). Commonly, standard protein solutions are digested to confirm the activity of trypsin and the digests are analyzed. This very general description is valid to most systems, but there are some exceptions. Immobilization can be carried out by copper-ion chelation [34] or by trypsin encapsulation in the pores of a mesoporous silica- $\mathrm{Fe}_{3} \mathrm{O}_{4}$ hybrid particle, the latter enabling size-selective protein digestion (only smaller proteins are digested, that can penetrate into the small pores where trypsin is located) [36]. Although trypsin is mostly used for digestion, alternatively, proteinase $\mathrm{K}$ can be immobilized [79] on magnetic particles for the same reason.

As an alternative to magnetic or agarose particles, PSDVB particles [58,140], gold nanoparticles [78], nanozeolites [81,82], sepharose [58], silica [43] and CPG [55] beads and glass fibers [76,77] can also be used for trypsin immobilization.

To compare the activity of the tryptic (or more generally any enzymatic) reactor versus free enzyme digestion - thus estimating the reactor efficiency - enzyme kinetic studies can be carried out. These are complementary measurements contributing to the full characterization of the reactor. In the case of trypsin, $\mathrm{N}_{\alpha}$-benzoyl-L-arginine ethyl ester (BAEE) is generally used for activity determination in continuous flow mode $[20,169,170]$. BAEE dissolved in $50 \mathrm{mM}$ Tris $(\mathrm{pH}=8)$ is transferred through the reactor and the effluent is measured spectrophotometrically to determine the amount of digested substrate. The reaction time can be calculated from the applied flow rate and the volume of the reactor and thus the activity can be calculated. This activity can be considered per the given amount of enzyme (if the amount of enzyme in the reactor is known), the given amount of particle (if the mass of

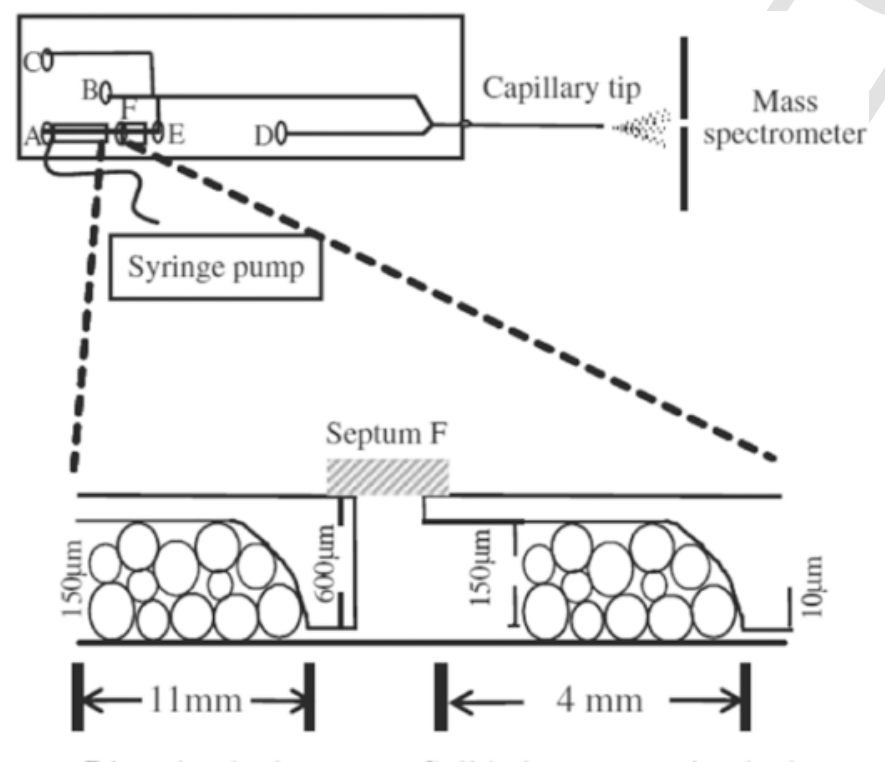

\section{Digestion bed Solid phase extraction bed}

Fig. 9. Schematic of a protein preparation chip, with integrated tryptic digestion and SPE beds, a double-T injector for CE and an electrospray tip. The lower drawings show the detail of the $150 \mu \mathrm{m}$ deep, $800 \mu \mathrm{m}$ wide "fat channels" in which $40-60 \mu \mathrm{m}$ diameter beads are trapped. The remaining channels are all $10 \mu \mathrm{m}$ deep and are $230 \mu \mathrm{m}$ wide near each of the fluid reservoirs, narrowing to $30 \mu \mathrm{m}$ wide for the majority of their length. (Adapted from Ref. [48]). used particle in the reactor is known) or the reactor itself. The activity value gives an estimation of reactor efficiency, however, they should be handled carefully, because these substrates undergo digestion much easier than the large proteins.

\subsection{Enzymatic operation for signal amplification}

On-chip quantification/detection of analytes is a rather unsolved issue, however, some detection methods for specific substances can be applied. $\mathrm{H}_{2} \mathrm{O}_{2}$ has a central role in these detection techniques: it can either be detected amperometrically or can be used to oxidize a non-fluorescent compound (e.g. luminol) to produce a fluorescent product. The use of multiple enzymes integrated into the same chip is common in these cases, including mostly the use of glucose oxidase (GOD), which generates $\mathrm{H}_{2} \mathrm{O}_{2}$ and horseradish peroxidase (HRP), which can produce fluorescent compound by oxidation using the $\mathrm{H}_{2} \mathrm{O}_{2}$ as an oxidizing agent.

\subsubsection{Amperometry}

As the simplest reactor, GOD was immobilized by glutaraldehyde coupling after silanization with APTES and the particles were used for glucose analysis by FIA [38]. A very similar microfluidic chip was described [39] and it was shown that the sensitivity of the device towards glucose depends on the length of the packing, as more glucose can be oxidized if a longer packing containing the immobilized enzyme is used. In another example, GOD was covalently immobilized on n-hydroxysuccinimide (NHS)-activated agarose [57]. In this work, the particles were retained by the reduction of the channel height at the end of the channel, without using frits. Glass beads of $50 \mu \mathrm{m}$ containing covalently immobilized GOD were retained with the help of a dam structure [53]. All these microchips were used for enzymatic oxidation of glucose to produce $\mathrm{H}_{2} \mathrm{O}_{2}$, which was detected amperometrically.

Graphene oxide - magnetic nanocomposites with adsorbed acetylcholinesterase (AChE) were packed into a PDMS chip for pesticide detection [83]. AChE activity is inhibited by dimethoate, which is usually used for the modelling of organophosphorus pesticides. This nanocomposite has a mean diameter of only $8 \mathrm{~nm}$. Acetylthiocholine (the substrate of AChE) is added to the inhibitor (which is the measured pesticide-like sample) and is converted by the enzyme into thiocholine, which is an amperometrically detectable electroactive compound. The extent of inhibition is proportional to the concentration of dimethoate.

\subsubsection{Fluorescent detection}

A creative application of immobilized enzymes is the form of multi-enzyme packings, when a packing contains 2 or more types of enzymes. This process can be a co-immobilization, when multiple enzyme types are located on the same bead (multi-enzyme bead) or single enzyme immobilizations, when 2 or more types of enzyme modified beads (single-enzyme beads) are retained stepwise or as a mixture. During the application of such multi-enzyme packings, some critical aspects should be considered: $i$, proper enzyme compartmentalization format (spatial distance between different enzymes) is essential due to the mass transport/diffusion loss of intermediates; ii, the product of a reaction can inhibit or completely deactivate other enzymes in the system; iii, different enzymes are likely to have different $\mathrm{pH}$ optima; iv, different enzymes may have different activity, there might be a slow - rate determining step in the enzymatic pathway.

Boehm et al. used $15.27 \mu \mathrm{m}$ streptavidin coated PS microspheres as packing material, onto which 3 types of enzymes were immobilized ( $\beta$-galactosidase, GOD, HRP) through biotin-streptavidin bioaffinity interaction [69]. This multi-enzymatic system was used for lactose detection. Different types of enzyme compartmentalization strategies were studied, namely immobilization of individual enzyme species (single- 
enzyme bead), immobilization of a mixture of the 3 enzymes (multi-enzyme bead) or coating the PDMS channel with enzymes using a different immobilization procedure [69]. It was found that the highest specific substrate conversion efficiency was obtained when the single-enzyme beads were used in 3 sequential steps.

In a similar study, Heo used 3 types of packed reactors in which biotinylated GOD and HRP were immobilized onto $9.95 \mu \mathrm{m}$ avidin-coated PS microspheres [70]. It was proved that co-immobilization of the 2 enzymes onto the same bead was a more efficient reactor format than creating single-enzyme beads and packing them as a mixture of beads or as 2 individual packings successively. The reason for its higher efficiency is the lack of diffusion loss of the intermediates in the case of co-immobilized enzymes due to shorter diffusion length.

The latter two examples might seem controversial, as the same enzymes were used in almost identical systems, however, the system of Boehm et al. contained a third enzyme - $\beta$-galactosidase - which could have made the difference. More importantly, Heo mentioned that $\mathrm{H}_{2} \mathrm{O}_{2}$ inhibition of GOD could have been eliminated, if it had been rapidly converted to the final, non-inhibiting product, which only happens in this co-immobilized, multi-enzyme reactor format. These publications may shed light on the fact that if one attempts to miniaturize multi-enzymatic pathways into microfluidic chips, there is no general rule to choose an optimal enzyme compartmentalization technique, but the thorough knowledge of the enzymatic reaction pathway and of the properties of each involved enzymes are essential to choose the correct compartmentalization strategy.

$5 \mu \mathrm{m}$ silica beads were used as solid support for covalent XOD and HRP immobilization and these particles were trapped in a reaction chamber of a glass microchip [44]. The packing process of the beads was not performed with the use of pressure, but by injecting the particles electrophoretically. With the help of this device, a non-fluorescent analyte, xanthine, was transformed with the multi-enzyme reactor into a fluorescent substance and detected. Similarly to GOD, XOD produced $\mathrm{H}_{2} \mathrm{O}_{2}$ from xanthine, which reacted with luminol in the presence of HRP, resulting in chemiluminescence.

$70 \mu \mathrm{m}$ nonporous glass particles with immobilized GOD were retained by bottlenecks created at the end of a reaction chamber for glucose quantitation. The produced $\mathrm{H}_{2} \mathrm{O}_{2}$ entered a second - detection chamber, where HRP was immobilized in a hydrogel microarray giving a fluorescent product (resorufin) from a non-fluorescent compound (amplex red) [54]. In a similar work, the same enzymes (GOD and HRP) were immobilized with bioaffinity linkage to streptavidin coated PS microbeads [68].

Diaphorase was immobilized covalently onto $2.7 \mu \mathrm{m}$ magnetic beads integrated into a PDMS chip for the conversion of non-fluorescent resazurin to fluorescent resorufin in the presence of NADH [37].

\subsubsection{Immunoassays}

Immunoassays can utilize the advantages offered by microbeads acting as solid supports with high surface area. With other words, the enzyme reactions of immunoassays can be carried out in a smaller volume. A large variety of biomolecules often used in immunoanalysis (e.g. proteins, antibodies, antigens, DNA, RNA) can be attached to the beads.

Human serum IgG antibodies were quantified in a microfluidic system with non-competitive immunoassay [40]. The Plexiglas microchip used in the experiment contained magnetically retained beads with covalently immobilized antigens from Helicobacter pylori, which can interact with human IgG antibodies. Then, an alkaline phosphatase enzyme-linked antibody specific for human IgG was applied, this enzyme converted p-aminophenyl phosphate to p-aminophenol, which was detected amperometrically in the chip with an integrated gold electrode.

PS beads $(45.6 \mu \mathrm{m}$ diameter) were retained in a glass microchip to integrate immunosorbent assay into chip platform [65]. After bead retention by a dam structure, IgA was adsorbed on the PS beads and it came into contact with colloidal gold conjugated anti-IgA. Laser-induced thermal lens microscopy was used for the detection. The same group used similar techniques to determine carcinoembryonic antigen (CEA) [66] and interferon- $\gamma$ [67]. In the latter two sandwich immunoassay systems, the PS beads (41.7 $\mu$ m diameter) were coated with anti-CEA antibody (or anti-interferon), which bonded CEA (or interferon). After washing out the matrices, a second antibody (anti-CEA or biotinylated anti-interferon) was injected, then after another washing, colloidal gold with anti-IgG (or streptavidin) functionalities were introduced to obtain the final complexes: PS bead - anti-CEA antibody (anti-interferon) - CEA (interferon) - anti-CEA (biotinylated anti-interferon) - anti-IgG (streptavidin) - colloidal gold (Fig. 10).

\section{First reaction}

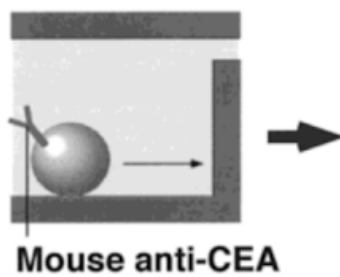

Mouse anti-CEA

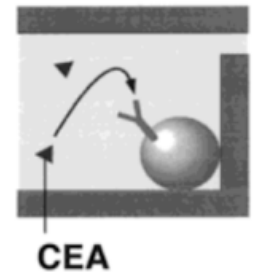

Third reaction

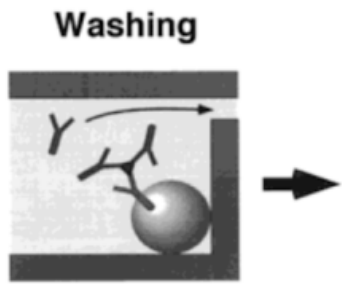

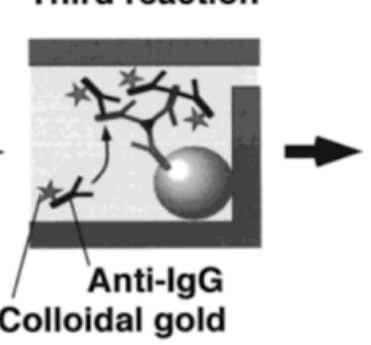

Washing

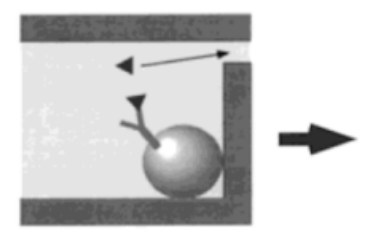

Washing

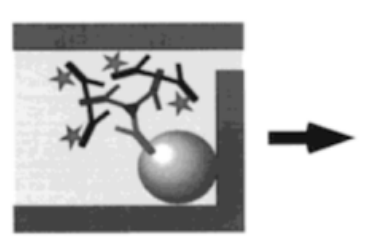

\section{Second reaction}

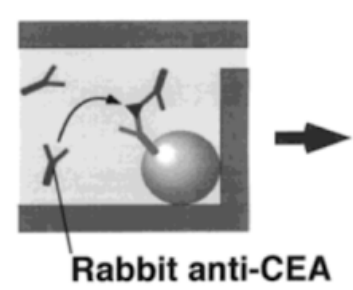

\section{Detection}

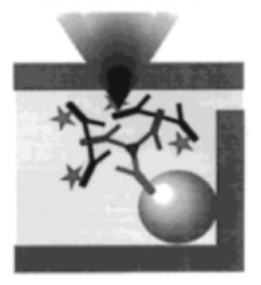

Fig. 10. Schematic illustrations of a microchip-based immunosorbent assay for the detection of carcinoembryonic antigen in human sera. (Adapted from Ref. [66]). 


\subsection{Synthesis, functional group conversions}

Synthesis - the process of the production of a given chemical substance - is usually not mentioned amongst the advantages or applications of microfluidic chips. However, it was shown in some cases that it has a valid position in the microreactor technology, usually when the reagents or the synthesized compounds are expensive and only a small portion is required to be synthesized (e.g. the microfluidic synthesis of fluorodeoxyglucose [171]), when the parameters of the synthesis are to be optimized [41] or when the applied particles are millimeter-scaled [59-64,71,72]. Also, several works can be found on different functional group conversions (hydrolysis [74,123], reduction [51], hydroxylation [138] and oxidation [73,75]).

Jussen et al. [41] synthesized (S) - 2-hydroxy-1-phenylpropan-1-one in a microchip IMER. Benzoylformate decarboxylase was immobilized through its 6-His tag at the C-terminal. The authors propose the system to be a great biocatalyst modelling system for parameter optimization.

Although not a microchip IMER, Ni-NTA agarose particles were used as solid supports for transketolase and transaminase immobilization via 6-His tag [172] in a $500 \mu \mathrm{m}$ (inner diameter) fluorinated ethylene propylene (FEP) tube. These two enzymes synthesized a diastereomer of 2-amino-1,3,4-butanetriol, which is regularly used in pharmaceutical syntheses. The work would have proven the potential importance of microchips in de novo (or other organic) syntheses, if this system was integrated into a chip.

\section{Conclusions and outlook}

There is a large number of reviews about the different aspects of construction and application of IMERs, which show the growing importance of these devices and technology. Here we focused on microfluidic enzyme reactors including particle-based supports. Particles play a major role in the miniaturization of enzymatic reactors since a large variety of particles (some containing already immobilized enzymes) are commercially available. Microchip IMERs have been widely used in the past 20 years, in this period various and creative methods have been introduced for both the immobilization of enzymes on the solid/liquid interface and the localization of particles within the microfluidic channel. Although these particles with enzymatic activities can be used in batch format, their integration into microfluidic flow systems is beneficial for high specific surface and for the possibility of simple parallelization.

Lately, the development of microchip IMERs has been a hot scientific topic amongst microfluidic research groups, but the use of particles in microchips - mostly in packing format - is still a challenge. The spreading of microchips will presumably increase in the future, therefore, particles will necessarily be used either in microchip IMERs or in microchip chromatographic/SPE systems. There is an ongoing argument whether particles would be exchanged by monolithic packings/columns in the future, but both monoliths and particles possess several advantages. A novel approach would be the combination of these two stationary phases in the form of hybrid monoliths with entrapped particles in microfluidic channels.

It has been shown that the application of several different enzymes has great potential in executing multiple step enzymatic reaction paths, however in almost every work, the same enzymatic reactions were studied (GOD - HRP system). Other reaction paths - with analytical or synthetic importance - might arise in the future, as well. If the product volume is a concern in synthetic reactions, it is questionable if extensive parallelization would solve productivity issues.
The manufacturing costs are essential to select the material/fabrication technology of microchips and the immobilized enzyme. A frequent approach is to apply inexpensive enzymes (e.g. trypsin) in microchips made from vulnerable, but low-cost polymers (e.g. PDMS) or glass. These chips can be considered disposable and should not be reused, thus cross-contamination of samples can be precluded. Immobilization offers the advantage of increasing enzyme stability/IMER reusability, but this feature is not utilized with these cheap microchip IMERs. Reusability and durability should only be a concern, when the employed enzyme is worth it (e.g. PNGase F).

Presently, microchip IMER development is mainly performed in research groups, unfortunately without any widespread pharmaceutical or industrial application of the IMERs. The reason behind this is that microchip technology still needs to improve chip robustness to obtain utile devices primarily for analytical tasks, where a large number of small-volume samples are analyzed with high throughput.

\section{Acknowledgments}

The research was supported by the EU and co-financed by the European Regional Development Fund under the project GINOP-2.3.2-15-2016-00008 and GINOP-2.3.3-15-2016-00004 project. The research was supported by ÚNKP-17-3-I-DE-4 project. The authors also acknowledge the financial support provided to this project by the National Research, Development and Innovation Office, Hungary (K111932).

\section{References}

[1] W. Ehrfeld, V. Hessel, H. Löwe, Microreactors, Wiley-VCH Verlag GmbH \& Co. KGaA, Weinheim, 2000.

[2] H. Yamaguchi, M. Miyazaki, Enzyme-immobilized reactors for rapid and efficient sample preparation in MS-based proteomic studies, Proteomics 13 (2013) 457-466.

[3] K.S. Elvira, X.C. i Solvas, R.C.R. Wootton, A.J. DeMello, The past, present and potential for microfluidic reactor technology in chemical synthesis, Nat. Chem. 5 (2013) 905-915.

[4] M. Miyazaki, H. Maeda, Microchannel enzyme reactors and their applications for processing, Trends Biotechnol. 24 (2006) 463-470.

[5] H. Wu, J. Zhai, Y. Tian, H. Lu, X. Wang, W. Jia, et al., Microfluidic enzymatic-reactors for peptide mapping: strategy, characterization, and performance, Lab Chip. 4 (2004) 588-597.

[6] L. Licklider, W.G. Kuhr, M.P. Lacey, T. Keough, M.P. Purdon, R. Takigiku, Online microreactors/capillary electrophoresis/mass spectrometry for the analysis of proteins and peptides, Anal. Chem. 67 (1995) 4170-4177.

[7] P.L. Urban, D.M. Goodall, N.C. Bruce, Enzymatic microreactors in chemical analysis and kinetic studies, Biotechnol. Adv. 24 (2006) 42-57.

[8] A.M. Girelli, E. Mattei, Application of immobilized enzyme reactor in on-line high performance liquid chromatography: a review, J. Chromatogr. B. 819 (2005) $3-16$.

[9] P. Tabeling, Introduction to Microfluidics, Oxford University Press, 2005.

[10] H. Yamaguchi, M. Miyazaki, T. Honda, M.P. Briones-Nagata, K. Arima, H. Maeda, Rapid and efficient proteolysis for proteomic analysis by protease-immobilized microreactor, Electrophoresis 30 (2009) 3257-3264.

[11] J. Krenkova, K. Kleparnik, F. Foret, Capillary electrophoresis mass spectrometry coupling with immobilized enzyme electrospray capillaries, J. Chromatogr. A. 1159 (2007) 110-118.

[12] L.N. Amankwa, W.G. Kuhr, Trypsin-modified fused-silica capillary microreactor for peptide mapping by capillary zone electrophoresis, Anal. Chem. 64 (1992) 1610-1613.

[13] H. Mao, T. Yang, P.S. Cremer, Design and characterization of immobilized enzymes in microfluidic systems, Anal. Chem. 74 (2002) 379-385.

[14] Y. Liu, H. Lu, W. Zhong, P. Song, J. Kong, P. Yang, et al., Multilayer-assembled microchip for enzyme immobilization as reactor toward low-level protein identification, Anal. Chem. 78 (2006) 801-808.

[15] A. Kecskemeti, J. Bako, I. Csarnovics, E. Csosz, A. Gaspar, Development of an enzymatic reactor applying spontaneously adsorbed trypsin on the surface of a PDMS microfluidic device, Anal. Bioanal. Chem. 409 (2017) 3573-3585.

[16] J.W. Cooper, J. Chen, Y. Li, C.S. Lee, Membrane-based nanoscale proteolytic reactor enabling protein digestion, peptide separation, and protein identification using mass spectrometry, Anal. Chem. 75 (2003) 1067-1074.

[17] Y. Jiang, C.S. Lee, On-line coupling of micro-enzyme reactor with micro-membrane chromatography for protein digestion, peptide separation, and protein identification using electrospray ionization mass spectrometry, J. Chromatogr. A. 924 (2001) 315-322 
[18] F. Xu, W.-H. Wang, Y.-J. Tan, M.L. Bruening, Facile trypsin immobilization in polymeric membranes for rapid, efficient protein digestion, Anal. Chem. 82 (2010) 10045-10051.

[19] J. Gao, J. Xu, L.E. Locascio, C.S. Lee, Integrated microfluidic system enabling protein digestion, peptide separation, and protein identification, Anal. Chem. 73 (2001) 2648-2655.

[20] J. Ma, Z. Liang, X. Qiao, Q. Deng, D. Tao, L. Zhang, et al., Organic-inorganic hybrid silica monolith based immobilized trypsin reactor with high enzymatic activity, Anal. Chem. 80 (2008) 2949-2956.

[21] E. Calleri, C. Temporini, E. Perani, C. Stella, S. Rudaz, D. Lubda, et al., Development of a bioreactor based on trypsin immobilized on monolithic support for the on-line digestion and identification of proteins, J. Chromatogr. A. 1045 (2004) 99-109.

[22] R. Nicoli, S. Rudaz, C. Stella, J.-L. Veuthey, Trypsin immobilization on an ethylenediamine-based monolithic minidisk for rapid on-line peptide mass fingerprinting studies, J. Chromatogr. A. 1216 (2009) 2695-2699.

[23] R. Nicoli, N. Gaud, C. Stella, S. Rudaz, J.-L. Veuthey, Trypsin immobilization on three monolithic disks for on-line protein digestion, J. Pharm. Biomed. Anal. 48 (2008) 398-407.

[24] S. Ota, S. Miyazaki, H. Matsuoka, K. Morisato, Y. Shintani, K. Nakanishi, High-throughput protein digestion by trypsin-immobilized monolithic silica with pipette-tip formula, J. Biochem. Biophys. Methods 70 (2007) 57-62.

[25] M. Ye, S. Hu, R.M. Schoenherr, N.J. Dovichi, On-line protein digestion and peptid mapping by capillary electrophoresis with post-column labeling for laser-induced fluorescence detection, Electrophoresis 25 (2004) 1319-1326.

[26] C. Temporini, E. Perani, E. Calleri, L. Dolcini, D. Lubda, G. Caccialanza, et al., Pronase-immobilized enzyme reactor: an approach for automation in glycoprotein analysis by LC/LC-ESI/MS ${ }^{\mathrm{n}}$, Anal. Chem. 79 (2007) 355-363.

[27] M.T. Dulay, Q.J. Baca, R.N. Zare, Enhanced proteolytic activity of covalently bound enzymes in photopolymerized sol gel, Anal. Chem. 77 (2005) 4604-4610.

[28] S. Feng, M. Ye, X. Jiang, W. Jin, H. Zou, Coupling the immobilized trypsin microreactor of monolithic capillary with $\mu$ RPLC - MS/MS for shotgun proteome analysis, J. Proteome Res. 5 (2006) 422-428.

[29] J. Duan, Z. Liang, C. Yang, J. Zhang, L. Zhang, W. Zhang, et al., Rapid protein identification using monolithic enzymatic microreactor and LC-ESI-MS/MS, Proteomics 6 (2006) 412-419.

[30] R.M. Schoenherr, M. Ye, M. Vannatta, N.J. Dovichi, CE-Microreactor-CE-MS/MS for protein analysis, Anal. Chem. 79 (2007) 2230-2238.

[31] A. Le Nel, J. Krenkova, K. Kleparnik, C. Smadja, M. Taverna, J.-L. Viovy, et al., On-chip tryptic digest with direct coupling to ESI-MS using magnetic particles, Electrophoresis 29 (2008) 4944-4947.

[32] M. Slovakova, N. Minc, Z. Bilkova, C. Smadja, W. Faigle, C. Futterer, et al., Use of self assembled magnetic beads for on-chip protein digestion, Lab Chip. 5 (2005) 935-942.

[33] J. Liu, S. Lin, D. Qi, C. Deng, P. Yang, X. Zhang, On-chip enzymatic microreacto using trypsin-immobilized superparamagnetic nanoparticles for highly efficient proteolysis, J. Chromatogr. A. 1176 (2007) 169-177.

[34] Y. Li, X. Xu, B. Yan, C. Deng, W. Yu, P. Yang, et al., Microchip reactor packed with metal-ion chelated magnetic silica microspheres for highly efficient proteolysis, $\mathrm{J}$ Proteome Res. 6 (2007) 2367-2375.

[35] Z. Bilkova, M. Slovakova, N. Minc, C. Futterer, R. Cecal, D. Horak, et al., Functionalized magnetic micro- and nanoparticles: optimization and application to $\mu$-chip tryptic digestion, Electrophoresis 27 (2006) 1811-1824.

[36] Q. Min, X. Zhang, R. Wu, H. Zou, J.-J. Zhu, A novel magnetic mesoporous silica packed S-shaped microfluidic reactor for online proteolysis of low-MW proteome, Chem. Commun. 47 (2011) 10725-10727.

[37] X. Liu, R.C. Lo, F.A. Gomez, Fabrication of a microfluidic enzyme reactor utilizing magnetic beads, Electrophoresis 30 (2009) 2129-2133.

[38] A. Nomura, S. Shin, O.O. Mehdi, J.-M. Kauffmann, Preparation, characterization, and application of an enzyme-immobilized magnetic microreactor for flow injection analysis, Anal. Chem. 76 (2004) 5498-5502.

[39] J. Sheng, L. Zhang, J. Lei, H. Ju, Fabrication of tunable microreactor with enzyme modified magnetic nanoparticles for microfluidic electrochemical detection of glucose, Anal. Chim. Acta 709 (2012) 41-46.

[40] S.V. Pereira, G.A. Messina, J. Raba, Integrated microfluidic magnetic immunosensor for quantification of human serum IgG antibodies to Helicobacter pylori, J. Chromatogr. B. 878 (2010) 253-257.

[41] D. Jussen, H. Soltner, B. Stute, W. Wiechert, E. von Lieres, M. Pohl, $\mu$ MORE: a microfluidic magnetic oscillation reactor for accelerated parameter optimization in biocatalysis, J. Biotechnol. 231 (2016) 174-182.

[42] M.A. Bynum, H. Yin, K. Felts, Y.M. Lee, C.R. Monell, K. Killeen, Characterization of IgG N-glycans employing a microfluidic chip that integrates glycan cleavage, sample purification, LC separation, and MS detection, Anal. Chem. 81 (2009) 8818-8825.

[43] A. Kecskemeti, A. Gaspar, Preparation and characterization of a packed bead immobilized trypsin reactor integrated into a PDMS microfluidic chip for rapid protein digestion, Talanta 166 (2017) 275-283.

[44] T. Richter, L.L. Shultz-Lockyear, R.D. Oleschuk, U. Bilitewski, D.J. Harrison, Bi-enzymatic and capillary electrophoretic analysis of non-fluorescent compounds in microfluidic devices: determination of xanthine, Sens. Actuators B. 81 (2002) 369-376.

[45] H.R. Luckarift, B.S. Ku, J.S. Dordick, J.C. Spain, Silica-immobilized enzymes for multi-step synthesis in microfluidic devices, Biotechnol. Bioeng. 98 (2007) 701-705
[46] C. Wang, R. Oleschuk, F. Ouchen, J. Li, P. Thibault, D.J. Harrison, Integration of immobilized trypsin bead beds for protein digestion within a microfluidic chip incorporating capillary electrophoresis separations and an electrospray mass spectrometry interface, Rapid Commun. Mass Spectrom. 14 (2000) 1377-1383.

[47] P. Liuni, T. Rob, D.J. Wilson, A microfluidic reactor for rapid, low-pressure prote olysis with on-chip electrospray ionization, Rapid Commun. Mass Spectrom. 24 (2010) 315-320.

[48] C. Wang, A.B. Jemere, D.J. Harrison, Multifunctional protein processing chip with integrated digestion, solid-phase extraction, separation and electrospray, Electrophoresis 31 (2010) 3703-3710.

[49] L.J. Jin, J. Ferrance, J.C. Sanders, J.P. Landers, A microchip-based proteolytic digestion system driven by electroosmotic pumping, Lab Chip. 3 (2003) 11-18

[50] M.T. Davis, T.D. Lee, M. Ronk, S.A. Hefta, Microscale immobilized protease reactor columns for peptide mapping by liquid chromatography/mass spectral analyses, Anal. Biochem. 224 (1995) 235-244.

[51] C. Berne, L. Betancor, H.R. Luckarift, J.C. Spain, Application of a microfluidic reactor for screening cancer prodrug activation using silica-immobilized nitrobenzene nitroreductase, Biomacromolecules 7 (2006) 2631-2636.

[52] S. Banu, G.M. Greenway, T. McCreedy, R. Shaddick, Microfabricated bioreactor chips for immobilised enzyme assays, Anal. Chim. Acta 486 (2003) 149-157.

[53] T. Ito, M. Kunimatsu, S. Kaneko, S. Ohya, K. Suzuki, Microfluidic device for the detection of glucose using a micro direct methanol fuel cell as an amperometric detection power source, Anal. Chem. 79 (2007) 1725-1730.

[54] D.N. Kim, Y. Lee, W.-G. Koh, Fabrication of microfluidic devices incorporating bead-based reaction and microarray-based detection system for enzymatic assay, Sens. Actuators B. 137 (2009) 305-312.

[55] E. Bonneil, M. Mercier, K.C. Waldron, Reproducibility of a solid-phase trypsin microreactor for peptide mapping by capillary electrophoresis, Anal. Chim. Acta 404 (2000) 29-45.

[56] J.M. Bolivar, C. Luley-Goedl, E. Leitner, T. Sawangwan, B. Nidetzky, Production of glucosyl glycerol by immobilized sucrose phosphorylase: options for enzyme fixation on a solid support and application in microscale flow format, J. Biotechnol. 257 (2017) 131-138.

[57] L. Blanes, M.F. Mora, C.L. do Lago, A. Ayon, C.D. Garcia, Lab-on-a-chip biosensor for glucose based on a packed immobilized enzyme reactor, Electroanalysis 19 (2007) 2451-2456.

[58] J.R. Freije, P.P.M.F.A. Mulder, W. Werkman, L. Rieux, H.A.G. Niederlander, E Verpoorte, et al., Chemically modified, immobilized trypsin reactor with improved digestion efficiency, J. Proteome Res. 4 (2005) 1805-1813.

[59] L.L. Woodcock, C. Wiles, G.M. Greenway, P. Watts, A. Wells, S. Eyley, Enzymatic synthesis of a series of alkyl esters using novozyme 435 in a packed-bed, miniaturized, continuous flow reactor, Biocatal. Biotransformation. 26 (2008) 501-507.

[60] M. Cvjetko, J. Vorkapic-Furac, P. Znidarsic-Plazl, Isoamyl acetate synthesis in imidazolium-based ionic liquids using packed bed enzyme microreactor, Process Biochem. 47 (2012) 1344-1350.

[61] A. Pohar, P. Znidarsic-Plazl, I. Plazl, Integrated system of a microbioreactor and a miniaturized continuous separator for enzyme catalyzed reactions, Chem. Eng. J. 189-190 (2012) 376-382.

[62] I. Dencic, S. de Vaan, T. Noel, J. Meuldijk, M. de Croon, V. Hessel, Lipase-based biocatalytic flow process in a packed-bed microreactor, Ind. Eng. Chem. Res. 52 (2013) 10951-10960.

[63] J. Wang, S.-S. Gu, H.-S. Cui, X.-Y. Wu, F.-A. Wu, A novel continuous flow biosynthesis of caffeic acid phenethyl ester from alkyl caffeate and phenethanol in a packed bed microreactor, Bioresour. Technol. 158 (2014) 39-47.

[64] S. Kundu, A.S. Bhangale, W.E. Wallace, K.M. Flynn, C.M. Guttman, R.A. Gross, et al., Continuous flow enzyme-catalyzed polymerization in a microreactor, J. Am. Chem. Soc. 133 (2011) 6006-6011.

[65] K. Sato, M. Tokeshi, T. Odake, H. Kimura, T. Ooi, M. Nakao, et al, Integration of an immunosorbent assay system: analysis of secretory human immunoglobulin A on polystyrene beads in a microchip, Anal. Chem. 72 (2000) 1144-1147.

[66] K. Sato, M. Tokeshi, H. Kimura, T. Kitamori, Determination of carcinoembryonic antigen in human sera by integrated bead-bed immunoasay in a microchip for cancer diagnosis, Anal. Chem. 73 (2001) 1213-1218.

[67] K. Sato, M. Yamanaka, H. Takahashi, M. Tokeshi, H. Kimura, T. Kitamori, Microchip-based immunoassay system with branching multichannels for simultaneous determination of interferon- $\gamma$, Electrophoresis 23 (2002) 734-739.

[68] G.H. Seong, R.M. Crooks, Efficient mixing and reactions within microfluidic channels using microbead-supported catalysts, J. Am. Chem. Soc. 124 (2002) 13360-13361.

[69] C.R. Boehm, P.S. Freemont, O. Ces, Design of a prototype flow microreactor for synthetic biology in vitro, Lab Chip. 13 (2013) 3426-3432.

[70] J. Heo, Spatial distance effect of bienzymes on the efficiency of sequential reactions in a microfluidic reactor packed with enzyme-immobilized microbeads, Anal. Sci. 30 (2014) 991-997.

[71] M. Bajic, I. Plazl, R. Stloukal, P. Znidarsic-Plazl, Development of a miniaturized packed bed reactor with $\omega$-transaminase immobilized in LentiKats $®$, Process Biochem. 52 (2017) 63-72.

[72] J. Madarasz, D. Nemeth, J. Bakos, L. Gubicza, P. Bakonyi, Solvent-free enzymatic process for biolubricant production in continuous microfluidic reactor, J. Clean. Prod. 93 (2015) 140-144.

[73] A. Blandino, M. Macias, D. Cantero, Immobilization of glucose oxidase within calcium alginate gel capsules, Process Biochem. 36 (2001) 601-606.

[74] M. Bucko, A. Vikartovska, I. Lacik, G. Kollarikova, P. Gemeiner, V. Patoprsty, et al., Immobilization of a whole-cell epoxide-hydrolyzing biocatalyst in sodium algi- 
nate-cellulose sulfate-poly(methylene-co-guanidine) capsules using a controlled encapsulation process, Enzym. Microb. Technol. 36 (2005) 118-126.

[75] A. Schenkmayerova, M. Bucko, P. Gemeiner, D. Trelova, I. Lacik, D. Chorvat, et al., Physical and bioengineering properties of polyvinyl alcohol lens-shaped particles versus spherical polyelectrolyte complex microcapsules as immobilisation matrices for a whole-cell Baeyer-Villiger monooxygenase, Appl. Biochem. Biotechnol. 174 (2014) 1834-1849.

[76] T. Liu, S. Wang, G. Chen, Immobilization of trypsin on silica-coated fiberglass core in microchip for highly efficient proteolysis, Talanta 77 (2009) 1767-1773.

[77] H. Fan, G. Chen, Fiber-packed channel bioreactor for microfluidic protein digestion, Proteomics 7 (2007) 3445-3449.

[78] Y. Liu, Y. Xue, J. Ji, X. Chen, J. Kong, P. Yang, et al., Gold nanoparticle assembly microfluidic reactor for efficient on-line proteolysis, Mol. Cell. Proteom. 6 (2007) 1428-1436.

[79] A. Le Nel, N. Minc, C. Smadja, M. Slovakova, Z. Bilkova, J.-M. Peyrin, et al., Controlled proteolysis of normal and pathological prion protein in a microfluidic chip, Lab Chip. 8 (2008) 294-301.

[80] Y. Li, B. Yan, C. Deng, W. Yu, X. Xu, P. Yang, et al., Efficient on-chip proteolysis system based on functionalized magnetic silica microspheres, Proteomics 7 (2007) 2330-2339.

[81] Y. Zhang, Y. Liu, J. Kong, P. Yang, Y. Tang, B. Liu, Efficient proteolysis system: a nanozeolite-derived microreactor, Small 2 (2006) 1170-1173.

[82] Y. Huang, W. Shan, B. Liu, Y. Liu, Y. Zhang, Y. Zhao, et al., Zeolite nanoparticle modified microchip reactor for efficient protein digestion, Lab Chip. 6 (2006) 534-539.

[83] R.-P. Liang, X.-N. Wang, C.-M. Liu, X.-Y. Meng, J.-D. Qiu, Construction of graphene oxide magnetic nanocomposites-based on-chip enzymatic microreactor for ultrasensitive pesticide detection, J. Chromatogr. A. 1315 (2013) 28-35.

[84] A.J. de Mello, N. Beard, Dealing with "real" samples: sample pre-treatment in microfluidic systems, Lab Chip. 3 (2003) $11 \mathrm{~N}-19 \mathrm{~N}$.

[85] G. Massolini, E. Calleri, Immobilized trypsin systems coupled on-line to separation methods: recent developments and analytical applications, J. Sep. Sci. 28 (2005) 7-21.

[86] M.A. Schwarz, P.C. Hauser, Recent developments in detection methods for microfabricated analytical devices, Lab Chip. 1 (2001) 1-6.

[87] S.C. Terry, J.H. Jerman, J.B. Angell, A gas chromatographic air analyzer fabricated on a silicon wafer, IEEE Trans. Electron Devices 26 (1979) 1880-1886.

[88] H. Becker, C. Gartner, Polymer microfabrication technologies for microfluidic systems, Anal. Bioanal. Chem. 390 (2008) 89-111.

[89] C.G. Khan Malek, Laser processing for bio-microfluidics applications (part I), Anal. Bioanal. Chem. 385 (2006) 1351-1361.

[90] Y. Xia, G.M. Whitesides, Soft Lithography, Angew. Chem. Int. Ed. 37 (1998) 550-575.

[91] M.J. Madou, Fundamentals of microfabrication: the science of miniaturization, 2nd ed., CRC Press, Boca Raton, 2002.

[92] L. Bousse, S. Mouradian, A. Minalla, H. Yee, K. Williams, R. Dubrow, Protein sizing on a microchip, Anal. Chem. 73 (2001) 1207-1212.

[93] G.M. Whitesides, E. Ostuni, S. Takayama, X. Jiang, D.E. Ingber, Soft lithography in biology and biochemistry, Annu. Rev. Biomed. Eng. 3 (2001) 335-373.

[94] A. Gaspar, F.A. Gomez, Application of surface plasmon resonance spectroscopy for adsorption studies of different types of components on poly(dimethylsiloxane), Anal. Chim. Acta 777 (2013) 72-77.

[95] H. Makamba, J.H. Kim, K. Lim, N. Park, J.H. Hahn, Surface modification of poly(dimethylsiloxane) microchannels, Electrophoresis 24 (2003) 3607-3619.

[96] A. Gaspar, A. Kecskemeti, F.A. Gomez, Use of surface plasmon resonance to study the adsorption of detergents on poly(dimethylsiloxane) surfaces, Electrophoresis 34 (2013) 1249-1252.

[97] D. Kim, A.E. Herr, Protein immobilization techniques for microfluidic assays, Biomicrofluidics 7 (2013) 41501-41547.

[98] E. Verpoorte, Beads and chips: new recipes for analysis, Lab Chip. 3 (2003) $60 \mathrm{~N}-68 \mathrm{~N}$.

[99] A. Manz, Y. Miyahara, J. Miura, Y. Watanabe, H. Miyagi, K. Sato, Design of an open-tubular column liquid chromatograph using silicon chip technology, Sens. Actuators B. 1 (1990) 249-255.

[100] S.C. Jacobson, R. Hergenroeder, L.B. Koutny, J.M. Ramsey, Open channel electrochromatography on a microchip, Anal. Chem. 66 (1994) 2369-2373.

[101] J.P. Kutter, Stephen C. Jacobson, N. Matsubara, J.M. Ramsey, Solvent-programmed microchip open-channel electrochromatography, Anal. Chem. 70 (1998) 3291-3297.

[102] G. Ocvirk, E. Verpoorte, A. Manz, M. Grasserbauer, H.M. Widmer, High-performance liquid-chromatography partially integrated onto a silicon chip, anal, Methods Instrum. 2 (1995) 74-82.

[103] G.A. Lord, D.B. Gordon, P. Myers, B.W. King, Tapers and restrictors for capillary electrochromatography and capillary electrochromatography-mass spectrometry, J. Chromatogr. A. 768 (1997) 9-16.

[104] M. Mayer, E. Rapp, C. Marck, G.J.M. Bruin, Fritless capillary electrochromatography, Electrophoresis 20 (1999) 43-49.

[105] L. Ceriotti, N.F. de Rooij, E. Verpoorte, An integrated fritless column for on-chip capillary electrochromatography with conventional stationary phases, Anal. Chem. 74 (2002) 639-647.

[106] T. Adam, K.K. Unger, M.M. Dittmann, G.P. Rozing, Towards the column bed stabilization of columns in capillary electroendosmotic chromatography: immobilization of microparticulate silica columns to a continuous bed, J. Chromatogr. A. 887 (2000) 327-337.
[107] A. Gaspar, M.E. Piyasena, F.A. Gomez, Fabrication of fritless chromatographic microchips packed with conventional reversed-phase silica particles, Anal. Chem. 79 (2007) 7906-7909.

[108] A. Gaspar, L. Hernandez, S. Stevens, F.A. Gomez, Electrochromatography in microchips packed with conventional reversed-phase silica particles, Electrophoresis 29 (2008) 1638-1642.

[109] A. Gaspar, A. Nagy, I. Lazar, Integration of ground aerogel particles as chromatographic stationary phase into microchip, J. Chromatogr. A. 1218 (2011) 1011-1015.

[110] A. Nagy, A. Gaspar, Packed multi-channels for parallel chromatographic separations in microchips, J. Chromatogr. A. 1304 (2013) 251-256.

[111] J.C. Lotters, W. Olthuis, P.H. Veltink, P. Bergveld, The mechanical properties of the rubber elastic polymer polydimethylsiloxane for sensor applications, J. Micromech. Microeng. 7 (1997) 145-147.

[112] J. Huft, C.A. Haynes, C.L. Hansen, Fabrication of high-quality microfluidic solid-phase chromatography columns, Anal. Chem. 85 (2013) 1797-1802.

[113] M.A. Unger, H.-P. Chou, T. Thorsen, A. Scherer, S.R. Quake, Monolithic microfab ricated valves and pumps by multilayer soft lithography, Science 288 (2000) 113-116.

[114] H. Yin, K. Killeen, R. Brennen, D. Sobek, M. Werlich, T. van de Goor, Microfluidic chip for peptide analysis with an integrated HPLC column, sample enrichment column, and nanoelectrospray tip, Anal. Chem. 77 (2005) 527-533.

[115] J.-W. Choi, K.W. Oh, A. Han, C.A. Wijayawardhana, C. Lannes, S. Bhansali, et al., Development and characterization of microfluidic devices and systems for magnetic bead-based biochemical detection, Biomed. Micro. 3 (2001) 191-200.

[116] H. Andersson, C. Jonsson, C. Moberg, G. Stemme, Self-assembled and self-sorted array of chemically active beads for analytical and biochemical screening, Talanta 56 (2002) 301-308.

[117] H. Qu, H. Wang, Y. Huang, W. Zhong, H. Lu, J. Kong, et al., Stable microstructured network for protein patterning on a plastic microfluidic channel: strategy and characterization of on-chip enzyme microreactors, Anal. Chem. 76 (2004) 6426-6433.

[118] Q. Zhang, J.-J. Xu, H.-Y. Chen, Glucose microfluidic biosensors based on immobilizing glucose oxidase in poly(dimethylsiloxane) electrophoretic microchips, J. Chromatogr. A. 1135 (2006) 122-126.

[119] Q. Zhang, J.-J. Xu, H.-Y. Chen, Patterning microbeads inside poly(dimethylsiloxane) microfluidic channels and its application for immobilized microfluidic enzyme reactors, Electrophoresis 27 (2006) 4943-4951.

[120] H. Kawaguchi, Functional polymer microspheres, Prog. Polym. Sci. 25 (2000) 1171-1210.

[121] M.H. Jazayeri, H. Amani, A.A. Pourfatollah, H. Pazoki-Toroudi, B. Sedighimoghaddam, Various methods of gold nanoparticles (GNPs) conjugation to antibodies, Sens. Bio-Sens. Res. 9 (2016) 17-22.

[122] J.M. Lee, H.K. Park, Y. Jung, J.K. Kim, S.O. Jung, B.H. Chung, Direct immobilization of protein $\mathrm{G}$ variants with various numbers of cysteine residues on a gold surface, Anal. Chem. 79 (2007) 2680-2687.

[123] J. Qiao, L. Qi, H. Yan, Y. Li, X. Mu, Microchip CE-LIF method for the hydrolysis of L-glutamine by using L-asparaginase enzyme reactor based on gold nanoparticle, Electrophoresis 34 (2013) 409-416.

[124] A.E. Persson, B.J. Schoeman, J. Sterte, J.-E. Otterstedt, The synthesis of discrete colloidal particles of TPA-silicalite-1, Zeolites 14 (1994) 557-567.

[125] M.A. Camblor, A. Corma, A. Mifsud, J. Perez-Pariente, S. Valencia, Synthesis of nanocrystalline zeolite beta in the absence of alkali metal cations, Stud. Surf. Sci. Catal. 105 (1997) 341-348.

[126] M. Tsapatsis, M. Lovallo, T. Okubo, M.E. Davis, M. Sadakata, Characterization of Zeolite L nanoclusters, Chem. Mater. 7 (1995) 1734-1741.

[127] W.-L. Liu, S.-H. Lo, B. Singco, C.-C. Yang, H.-Y. Huang, C.-H. Lin, et al., Novel trypsin-FITC@MOF bioreactor efficiently catalyzes protein digestion, J. Mater. Chem. B. 1 (2013) 928-932.

[128] Y. Lv, X. Tan, F. Svec, Preparation and applications of monolithic structures containing metal-organic frameworks, J. Sep. Sci. 40 (2017) 272-287.

[129] L. Wen, A. Gao, Y. Cao, F. Svec, T. Tan, Y. Lv, Layer-by-layer assembly of metal-organic frameworks in macroporous polymer monolith and their use for enzyme immobilization, Macromol. Rapid Commun. 37 (2016) 551-557.

[130] L. Shangguan, L. Zhang, Z. Xiong, J. Ren, R. Zhang, F. Gao, et al., Investigation of bi-enzymatic reactor based on hybrid monolith with nanoparticles embedded and its proteolytic characteristics, J. Chromatogr. A. 1388 (2015) 158-166.

[131] A. Pohar, I. Plazl, P. Znidarsic-Plazl, Lipase-catalyzed synthesis of isoamyl acetate in an ionic liquid/n-heptane two-phase system at the microreactor scale, Lab Chip. 9 (2009) 3385-3390.

[132] R.A. Sheldon, Cross-linked enzyme aggregates as industrial biocatalysts, Org. Process Res. Dev. 15 (2011) 213-223.

[133] M. Conejero-Muriel, I. Rodriguez-Ruiz, C. Verdugo-Escamilla, A. Llobera, J.A. Gavira, Continuous sensing photonic lab-on-a-chip platform based on cross-linked enzyme crystals, Anal. Chem. 88 (2016) 11919-11923.

[134] M. Conejero-Muriel, I. Rodriguez-Ruiz, S. Martinez-Rodriguez, A. Llobera, J.A. Gavira, McCLEC, a robust and stable enzymatic based microreactor platform, Lab Chip. 15 (2015) 4083-4089.

[135] T. Honda, M. Miyazaki, H. Nakamura, H. Maeda, Facile preparation of an enzyme-immobilized microreactor using a cross-linking enzyme membrane on a microchannel surface, Adv. Synth. Catal. 348 (2006) 2163-2171.

[136] A.M. Hickey, L. Marle, T. McCreedy, P. Watts, G.M. Greenway, J.A. Littlechild, Immobilization of thermophilic enzymes in miniaturized flow reactors, Biochem. Soc. Trans. 35 (2007) 1621-1623. 
[137] H. Al-Lawati, P. Watts, K.J. Welham, Efficient protein digestion with peptide separation in a micro-device interfaced to electrospray mass spectrometry, Analyst 131 (2006) 656.

[138] A. Srinivasan, H. Bach, D.H. Sherman, J.S. Dordick, Bacterial P450-catalyzed polyketide hydroxylation on a microfluidic platform, Biotechnol. Bioeng. 88 (2004) 528-535.

[139] A.J. Percy, D.C. Schriemer, Rheostatic control of tryptic digestion in a microscale fluidic system, Anal. Chim. Acta 657 (2010) 53-59.

[140] S. Wang, F.E. Regnier, Proteolysis of whole cell extracts with immobilized enzyme columns as part of multidimensional chromatography, J. Chromatogr. A 913 (2001) 429-436.

[141] K.-D. Vorlop, M. Jekel, Process for preparing a biocatalyst with a polyvinyl alcoho gel and biocatalyst produced by this process, 198 (27), 1998.

[142] C.J. Martinez, J.W. Kim, C. Ye, I. Ortiz, A.C. Rowat, M. Marquez, et al., A microfluidic approach to encapsulate living cells in uniform alginate hydrogel microparticles, Macromol. Biosci. 12 (2012) 946-951.

[143] A.G. Hati, D.C. Bassett, J.M. Ribe, P. Sikorski, D.A. Weitz, B.T. Stokke, Versatile, cell and chip friendly method to gel alginate in microfluidic devices, Lab Chip. 16 (2016) 3718-3727.

[144] J. Krenkova, F. Foret, Immobilized microfluidic enzymatic reactors, Electrophoresis 25 (2004) 3550-3563.

[145] H. Yamaguchi, T. Honda, M. Miyazaki, Application of enzyme-immobilization technique for microflow reactor, J. Flow. Chem. 6 (2016) 13-17.

[146] J. Wiesbauer, J.M. Bolivar, M. Mueller, M. Schiller, B. Nidetzky, Oriented immobilization of enzymes made fit for applied biocatalysis: non-covalent attachment to anionic supports using Zbasic2 module, ChemCatChem 3 (2011) 1299-1303.

[147] G.H. Seong, J. Heo, R.M. Crooks, Measurement of enzyme kinetics using a continuous-flow microfluidic system, Anal. Chem. 75 (2003) 3161-3167.

[148] D. Josic, J.G. Clifton, Use of monolithic supports in proteomics technology, J. Chromatogr. A. 1144 (2007) 2-13.

[149] W.R. Vandaveer, S.A. Pasas-Farmer, D.J. Fischer, C.N. Frankenfeld, S.M. Lunte, Recent developments in electrochemical detection for microchip capillary electrophoresis, Electrophoresis 25 (2004) 3528-3549.

[150] J.P. McMullen, K.F. Jensen, Integrated microreactors for reaction automation: new approaches to reaction development, Annu. Rev. Anal. Chem. 3 (2010) 19-42.

[151] K.B. Mogensen, H. Klank, J.P. Kutter, Recent developments in detection for microfluidic systems, Electrophoresis 25 (2004) 3498-3512.

[152] R.J. Meagher, A.V. Hatch, R.F. Renzi, A.K. Singh, An integrated microfluidic platform for sensitive and rapid detection of biological toxins, Lab Chip. 8 (2008) 2046-2053.

153] K.W. Ro, K. Lim, B.C. Shim, J.H. Hahn, Integrated light collimating system for extended optical-path-length absorbance detection in microchip-based capillary electrophoresis, Anal. Chem. 77 (2005) 5160-5166.

[154] L. Malic, A.G. Kirk, Integrated miniaturized optical detection platform for fluorescence and absorption spectroscopy, Sens. Actuators A. 135 (2007) 515-524.

[155] S.-A. Leung, R.F. Winkle, R.C.R. Wootton, A.J. DeMello, A method for rapid reaction optimisation in continuous-flow microfluidic reactors using online Raman spectroscopic detection, Analyst 130 (2005) 46-51.

[156] H. Wensink, F. Benito-Lopez, D.C. Hermes, W. Verboom, H.J.G.E. Gardeniers, D.N Reinhoudt, et al., Measuring reaction kinetics in a lab-on-a-chip by microcoil NMR, Lab Chip. 5 (2005) 280-284.

[157] P.I. Koczka, E. Bodoki, A. Gaspar, Application of capacitively coupled contactless conductivity as an external detector for zone electrophoresis in poly(dimethylsiloxane) chips, Electrophoresis 37 (2016) 398-405.

[158] A. R. de Boer, B. Bruyneel, J.G. Krabbe, H. Lingeman, W.M.A. Niessen, H. Irth, A microfluidic-based enzymatic assay for bioactivity screening combined with capillary liquid chromatography and mass spectrometry, Lab Chip. 5 (2005) 1286-1292.

[159] J. Lee, H.K. Musyimi, S.A. Soper, K.K. Murray, Development of an automated digestion and droplet deposition microfluidic chip for MALDI-TOF MS, J. Am. Soc Mass Spectrom. 19 (2008) 964-972.

[160] S. Koster, E. Verpoorte, A decade of microfluidic analysis coupled with electrospray mass spectrometry: an overview, Lab Chip. 7 (2007) 1394-1412.
[161] J. Duan, L. Sun, Z. Liang, J. Zhang, H. Wang, L. Zhang, et al., Rapid protein digestion and identification using monolithic enzymatic microreactor coupled with nano-liquid chromatography-electrospray ionization mass spectrometry, J. Chromatogr. A. 1106 (2006) 165-174.

[162] J. Krenkova, Z. Bilkova, F. Foret, Chararacterization of a monolithic immobilized trypsin microreactor with on-line coupling to ESI-MS, J. Sep. Sci. 28 (2005) $1675-1684$

[163] I.M. Lazar, J. Grym, F. Foret, Microfabricated devices: a new sample introduction approach to mass spectrometry, Mass Spectrom. Rev. 25 (2006) 573-594.

[164] D.L. DeVoe, C.S. Lee, Microfluidic technologies for MALDI-MS in proteomics, Electrophoresis 27 (2006) 3559-3568.

[165] M. Brivio, R.H. Fokkens, W. Verboom, D.N. Reinhoudt, N.R. Tas, M. Goedbloed, et al., Integrated microfluidic system enabling (bio)chemical reactions with on-line MALDI-TOF mass spectrometry, Anal. Chem. 74 (2002) 3972-3976.

[166] M.R. Wilkins, J.-C. Sanchez, A.A. Gooley, R.D. Appel, I. Humphery-Smith, D.F. Hochstrasser, et al., Progress with proteome projects: why all proteins expressed by a genome should be identified and how to do it, Biotechnol. Genet. Eng. Rev. 13 (1996) 19-50.

[167] M.P. Washburn, D. Wolters, J.R. Yates, Large-scale analysis of the yeast proteome by multidimensional protein identification technology, Nat. Biotechnol. 19 (2001) 242-247.

[168] Y. Li, R. Wojcik, N.J. Dovichi, A replaceable microreactor for on-line protein digestion in a two-dimensional capillary electrophoresis system with tandem mass spectrometry detection, J. Chromatogr. A. 1218 (2011) 2007-2011.

[169] D.S. Peterson, T. Rohr, F. Svec, J.M.J. Frechet, Enzymatic microreactor-on-a-chip: protein mapping using trypsin immobilized on porous polymer monoliths molded in channels of microfluidic devices, Anal. Chem. 74 (2002) 4081-4088.

[170] Y. Liu, W. Zhong, S. Meng, J. Kong, H. Lu, P. Yang, et al., Assembly-controlled biocompatible interface on a microchip: strategy to highly efficient proteolysis, Chem. - A Eur. J. 12 (2006) 6585-6591, https://doi.org/10.1002/chem.200501622.

[171] A.M. Elizarov, R.M. van Dam, Y.S. Shin, H.C. Kolb, H.C. Padgett, D. Stout, et al., Design and optimization of coin-shaped microreactor chips for PET radiopharmaceutical synthesis, J. Nucl. Med. 51 (2010) 282-287.

[172] A. Abdul Halim, N. Szita, F. Baganz, Characterization and multi-step transketolase- $\omega$-transaminase bioconversions in an immobilized enzyme microreactor (IEMR) with packed tube, J. Biotechnol. 168 (2013) 567-575.

[173] S. Liu, H. Bao, L. Zhang, G. Chen, Efficient proteolysis strategies based on microchip bioreactors, J. Proteom. 82 (2013) 1-13.

[174] L. Hajba, A. Guttman, Continuous-flow biochemical reactors: biocatalysis, bioconversion, and bioanalytical applications utilizing immobilized microfluidic enzyme reactors, J. Flow. Chem. 6 (2016) 8-12.

[175] S.A. Ansari, Q. Husain, Potential applications of enzymes immobilized on/in nano materials: a review, Biotechnol. Adv. 30 (2012) 512-523.

[176] M. Safdar, J. Sproß, J. Janis, Microscale immobilized enzyme reactors in proteomics: latest developments, J. Chromatogr. A. 1324 (2014) 1-10.

[177] X. Yao, Y. Zhang, L. Du, J. Liu, J. Yao, Review of the applications of microreactors, Renew. Sustain. Energy Rev. 47 (2015) 519-539.

[178] A.A. Homaei, R. Sariri, F. Vianello, R. Stevanato, Enzyme immobilization: an update, J. Chem. Biol. 6 (2013) 185-205.

[179] Y. Asanomi, H. Yamaguchi, M. Miyazaki, H. Maeda, Enzyme-immobilized microfluidic process reactors, Molecules 16 (2011) 6041-6059.

[180] J. Nemethne-Sovago, M. Benke, Microreactors: a new concept for chemical synthesis and technological feasibility, Mater. Sci. Eng. 39 (2014) 89-101.

[181] F.E. Regnier, J. Kim, Accelerating trypsin digestion: the immobilized enzyme reactor, Bioanalysis 6 (2014) 2685-2698.

[182] K. Ariga, Q. Ji, T. Mori, M. Naito, Y. Yamauchi, H. Abe, et al., Enzyme nanoarchitectonics: organization and device application, Chem. Soc. Rev. 42 (2013) $6322-6345$.

[183] M.P.C. Marques, P. Fernandes, Microfluidic devices: useful tools for bioprocess intensification, Molecules 16 (2011) 8368-8401.

[184] S. Matosevic, N. Szita, F. Baganz, Fundamentals and applications of immobilized microfluidic enzymatic reactors, J. Chem. Technol. Biotechnol. 86 (2011) 325-334. 